das Befremdende dieser Erscheinung schwindet, wenn man die Elasticität der Rechtssymbolik bedenkt und einsieht, dass es sich hier um Verwendung des Symbols in übertragener Bedeutung, dass es sich im Grunde um die Idee des Verzichts, der Entsagung handelt. Dazu kommt, dass sich in aller Welt Fälle symbolischer Zerstörung bei ähnlichen Anlässen, z. B. beim Abschlusse der Ehe, bei eidlicher Betheuerung nachweisen lassen. Auf einem altägyptischen Denkmale zerbrechen die Beduinen vor Sethos I. zum Zeichen der Ergebung ihre Speere. Indische Bergvölker sollen bei Schliessung ihrer Verträge Strohhalme brechen. Und in Hermannsburg ging der Richter mit zwei Stäben in's Halsgericht: den weissen brach er über dem zum Tode Verurtheilten, den bunten im Falle der Freisprechung des Angeklagten.

\title{
IV. \\ Die Grundlagen der mittelalterlichen Verfassung Deutschlands und Frankreichs.
}

Eine Litteraturstudie ${ }^{1}$ ).

Von

\section{Ulrich Stutz.}

Von all den werthvollen Beiträgen zur mittelalterlichen Rechtsgeschichte, die uns die letzten Jahre brachten, kann kaum einer mit so viel Grund Anspruch auf unser lebhaftestes Interesse und unser gründlichstes Studium erheben wie die "Deutsche und französische Verfassungsgeschichte vom 9. bis zum 14. Jahrhundert" von Ernst Mayer. Die Frucht langjähriger Arbeit und einer Denk-

1) Zugleich statt einer besondem Anzeige von:

Ernst Mayer, Deutsche und französische Verfassungsgeschichte vom

9. bis zum 14. Jahrhundert, Leipzig, A. Deichertsche Verlagsbuch-

handlung 1899 1. Bd. XXII u. 554 S., 2. Bd. XIII u. $438 \mathrm{~S}$.

Derselbe, Hansa u. Hasbannus im nordfranzösischen Recht, Leipzig,

A. Deichertsche Verlagsbuchhandlung $190047 \mathrm{~S}$. (Sonderabdruck aus 
kraft von seltener Schärfe und Eigenart schliesst sie einen wahren Reichthum kostbaren Materials und einen ganz erstaunlichen Schatz selbständiger Beobachtung ein. Die Kritik wird festzustellen haben, in wie weit Mayers Ergebnisse auch richtig und haltbar sind. Allein zu solcher Kritik scheint mir die Zeit noch nicht gekommen zu sein. Zwar regt sich schon jetzt da und dort der Widerspruch. In welchem aufmerksamen Leser würden auch nicht alsbald Bedenken wach sowohl gegenüber Mayers Methode, wie auch angesichts mancher Einzelheiten! Jedoch man hüte sich, daraus vorschnell ein Urtheil zu machen. Es könnte sonst bald als revisionsbedürftig sich erweisen. Einer so originellen Leistung wohnt die Versuchung zu raschem Widerspruch geradezu inne. Sie reizt aber auch zu stets neuer Prüfung, bei der man sich nicht selten nach und nach mit dem befreundet, was auf den ersten Blick ganz unannehmbar schien. Das endgültige Urtheil will also reiflich erwogen sein. Und vor Allem, es muss auf das Ganze gehen. Mehr als ein Stein kann ausfallen oder locker werden, ohne dass ein so vielfach gestütztes Gebäude darum ins Wanken zu gerathen braucht. Die erste Voraussetzung aber für eine solche auf das Ganze gerichtete Kritik ist die Beherrschung des Ganzen. Diese ergiebt sich bei Mayers Werk nicht schon aus einer, wenn auch noch so sorgfältigen Lesung. Thm mangelt eben, wie das ja gerade bei nachhaltiger und tiefgründiger Gedankenarbeit nur zu leicht der Fall ist, die Abklärung und Zusammenfassung. Nicht dass man auch nur einen Augenblick daran zweifelte, dass der Verfasser genau weiss, was er will, und dass er ein vollständiges, in den Grundzügen klares Gesammtbild seiner Ergebnisse in sich herumträgt. Aber es scheint ihm im Laufe der Untersuchung so

der Festgabe der Würzburger Rechts- u. Staatswissenschaftlichen Facultät für Heinrich Dernburg).

Philipp Heck, Die Biergelden, Halle, Max Niemeyer $190072 \mathrm{~S}$. (Sonderabzug aus der Festgabe der Halleschen Juristenfacultät für Heinrich Dermburg).

Fritz Kiener, Dr. phil., Verfassungsgeschichte der Provence seit der

Ostgothenherrschaft bis zur Errichtung der Konsulate (510-1200), Leipzig, Dyksche Buchhandlung 1900 XII u. 295 S. mit einer Karte. 
selbstverständlich geworden zu sein, dass er es für sich behält oder doch dem Leser nicht mit solcher Bestimmtheit und in solcher Geschlossenheit vorführt, wie er, der Neuling in diesen Gedankengängen, es wünschen möchte ${ }^{1}$ ). Dem Leser bleibt also nichts Anderes übrig, als das Versäumte selbst nachzuholen und sich durch eigene Arbeit die Uebersicht über das Ganze und Rechenschaft im Einzelnen zu geben. Als ein Beitrag zu dieser Arbeit will die nachfolgende Studie angesehen werden. Sie soll keine Kritik sein, sondern eine Vorarbeit für die Kritik, und sie soll als solche dem Interesse Ausdruck zu verleihen suchen, das unsere Fachwissenschaft an Mayers Werk nimmt, und von dem insbesondere der Urheber dieser Betrachtungen durchdrungen ist.

$$
\text { I. }
$$

Zwei Richtlinien ist Mayer gefolgt, als er seinen Bau aufführte. Die eine, wenn ich so sagen darf, senkrechte, zielte auf die Herkunft der einzelnen Einrichtungen ab; die andere, mehr wagrechte, schied sie nach ihrer mehr oder weniger ausgesprochenen Zugehörigkeit zum Herrschaftsgebiet der öffentlichen oder der privaten Gewalt.

Die erste Richtlinie ergab sich aus Mayers eigenthümlicher Stellung zu den Quellen. Die Chroniken und vor allem die Urkunden achtet er gering. Er zieht sie zwar auch zu Rathe, ja er beherrscht sie selbständig. Speziell eine Vernachlässigung des Urkundenmaterials kann ihm durchaus nicht vorgeworfen werden. Im Gegentheil, von einzelnen Urkunden macht er sogar einen viel zu weitgehenden, durchaus unzulässigen Gebrauch, wie z. B. von einer Füllenho in Overyssel betreffenden Vergabung, die er fast als eine gesetzliche Offenbarung über die Hundertschaft ansieht ${ }^{2}$ ), und mit der allein er sich im Grunde genommen dieses so oft

1) Es ist z. B. für Mayers Darstellungsweise charakteristisch, dass man die kürzeste und genaueste Fassung seiner Ergebnisse oft nicht in dem der betreffenden Materie gewidmeten Abschnitte, sondern an anderer Stelle, etwa gelegentlich einer Vorwegnahme oder Wiederholung findet; vgl. beispielsweise I. S. 307 mit S. $384 \mathrm{ff}$. über das Schöffeninstitut. — ${ }^{2}$ ) I. S. 412 f., 417, 422, 435 , 
untersuchte Gebilde zurechtlegt. Doch solch vereinzelter Ueberschätzung steht als Regel eine ungerechtfertigte Unterschätzung gegenüber. Mayer ist der Ansicht, dass die Geschichtsquellen eine sehr mangelhafte und sehr einseitige Auskunft geben: mangelhafte, weil ihren Urhebern - zumal "bei dem klerikalen Sinne der alten Berichterstatter" - das Verständniss für das juristisch Relevante und für das rechtliche Werden völlig abgehe, einseitige, weil sie fast nur über das berichteten, was irgendwie auf die Kirche Bezug habe, insbesondere über zahllose Vergabungen der Grossen, während sie stumm blieben über alle anderen Verhältnisse der staatlichen Gesellschaft, vor allem über die Rechtslage der geringeren Freien ${ }^{1}$ ), aber auch über Vorgänge in den höheren Schichten, die, etwa wie die Entwickelung des Pfalzgrafenamtes $^{2}$ ), die Kirche nicht berührten. Es läge nahe, darauf zu erwidern, dass in damaliger Zeit die Thatsachen und Ereignisse viel unmittelbarer und mit viel grösserer Gewalt auf das Recht einwirkten als heutzutage, wo vielfach Vorstellungen und Theorien, die den Thatsachen ganz fern stehen, die Rechtsbildung und Rechtsentwickelung mafsgebend beeinflussen, sodass also gerade der Rechtshistoriker des 9. und der folgenden Jahrhunderte allen Anlass hat, dem Gange der Ereignisse aufmerksam zu folgen und unter sorgfältigster Verwerthung der Geschichtsquellen immer den Anschluss an die Thatsachen zu suchen. Man könnte auch einwenden, dass die Kirche damals so ziemlich alles in ihren Bereich gezogen habe, sodass die vorwiegend kirchliche Herkunft der Geschichtsquellen zwar vielleicht deren Einseitigkeit aber nicht eine erhebliche Unvollständigkeit bedinge. Und was insbesondere die Urkunden anlangt, so wäre einerseits auf den reichen Schatz der Placita hinzuweisen, die doch lediglich Aeusserungen einer staatlichen Funktion sind, und anderseits auf jene nicht bloss in Italien sondern auch diesseits der Alpen nicht ganz seltenen Privaturkunden, die zwar in die kirchlichen Archive gewandert und durch sie uns erhalten worden sind, aber nur als Rechtstitel, als instrumenta antiqua, nicht zum Zweck der Vergabung selbst. Gewiss verbreitet

1) I S. VII. $-{ }^{2}$ ) II S. 337 . Siehe auch I S. 400 N. 65 , II S. 345. 
das Urkundenmaterial kein gleichmäfsiges Licht über alle Theile des mittelalterlichen Rechtes, schon deswegen nicht, weil, wie Gierke einmal anlässlich des Versuchs, an Hand der Urkunden die Nichtexistenz der Schöffenbarfreien darzuthun, mir gegenüber treffend sich ausdrückte, die Urkunden so etwas wie ein Sieb sind, durch das leicht durchfällt, was nicht Regel und alltäglich ist. Aber das alles mahnt doch nur zu vorsichtiger, kritischer Benutzung der Urkunden und zwingt keineswegs dazu, sie für die nachfränkische Zeit, deren hauptsächlichste und beredteste Zeugnisse sie nun einmal sind, ihres bisher unangefochten innegehabten Amtes zu entsetzen.

Doch mir kommt es an dieser Stelle, an der es mir nichi sowohl um Kritik als um Orientirung zu thu ist, noch weit mehr darauf an, dass Mayer durch diese Auffassung gewissermalsen von seinem Gegenstand abgedrängt oder wenigstens weit über ihn hinaus geführt worden ist. Nach Ablehnung der Urkunden und der Geschichtsquellen blieb ihm nämlich nicht viel Anderes übrig, als auf die Rechtsbücher abzustellen, zu denen Mayer auch sonst das grösste Vertrauen hat, "weil sie auch von den Seiten der Sache sprechen, die in den Urkunden nicht berührt werden, weil sie gezwungen sind, generell zu reden und damit die Verhältnissz juristisch aufzufassen und vor allem, weil ihre Verfasser - überwiegend weltliche Praktiker - weit mehr Sachkenntniss besitzen als die geistlichen Chronisten und Urkundenschreiber "1). Nun sind freilich diese Rechtsbücher verhältnissnäfsig jung; hüben und drüben setzen sie ungefähr mit dem 13. Jahrhundert ein. Gerade mit Rücksicht darauf lässt Mayer seine Verfassungsgeschichte bis zum 14. Jahrhundert gehen. Tür die ältere Rechtsgeschichte waren solche Quellen nur vermittelst Rückschlusses verwendbar. In der That beruhen so ziemlich alle Ergebnisse Mayers auf Rückschlüssen. Dabei geht er von der Voraussetzung aus, dass die Rechtsbücher einen reichen Grundstock alten Rechtes enthalten, der sich kraft „der Zähigkeit der Rechtsformen“ aus ältester und älterər Zeit bis an die Grenze des späteren Mittelalters

\footnotetext{
1) I S. VIII.
} 
und über diese hinaus behauptet hätte. Seine Aufgabe erblickte er also darin, diesen Kern herauszuschälen. Er bediente sich dazu der Vergleichung der deutschen und französischen Rechtsverhältnisse. „Darf man ja nirgends die Möglichkeit einer blossen Parallelentwickelung ausser Acht lassen, so wird eine solche doch fast nicht in Betracht kommen, wo eine individuell geformte Einrichtung sich gleichmä'sig in Deutschland und Frankreich findet" ${ }^{1}$ ). Wo also Uebereinstimmung besteht, da haben das deutsche und das französische Recht eine gemeinsame Wurzel, die sich bei weiter fortgesetzter Untersuchung entweder als fränkisch oder darüber hinaus gar als germanisch oder römisch erweist; wo nicht, da steht man vor specifisch deutschen oder französischen Bildungen. Und so verfährt denn auch Mayer im Einzelnen. In einer Materie nach der andern wird der Inhalt meist späterer deutscher und französischer Quellen gegenübergestellt, auf Verschiedenheit oder Uebereinstimmung untersucht und im letzteren Falle auf dem fränkischen, germanischen oder römischen Konto gebucht. Die Rechnung scheint überaus einfach und sicher. Sie ist es auch bis zu einem gewissen Grade. Sie hat nur das Missliche, dass man bei ihr in Versuchung kommt, Uebereinstinmung anzunehmen, wo eine solche gar nicht vorliegt. Man müsste eine viel genauere Einsicht in die Verhältnisse lesitzen, unter denen jede einzelne von den zahlreichen in Betracht kommenden Quellen entstand, und nach denen sie demgemäls auch zu beurtheilen ist, als dies überhaupt und insbesondere für den Verfasser eines so gross angelegter Werkes möglich ist. Denn so kann keine Rede sein von einer völligen Sicherheit darüber, dass man nicht eine Gleichheit, die bloss Schein ist, oder auf Zufall beruht oded das Ergebniss ähnlicher äusserer Vereinständungen, inslesondere übereinstimmender wirthschaftlicher Bedingungen, hildet, für innere Uebereinstimmung nimmt. Das Verfahren le:det eben, selbst wenn man von der Willkür absieht, die rach festgestellter Identität bei der Zutheilung an die ränkische oder germanische oder römische Masse leicht nit unter-

1) I S. VIII; vgl. I S, 69. 
läuft, und zumal wenn es in so grossem Malsstabe und so schablonenhaft angewendet wird, an einer starken Fehlerquelle zu Gunsten des vorausgesetzten und ja gewiss auch vorhandenen gemeinsamen Grundstocks und zu Ungunsten der selbständigen Sonderentwickelung. Kein Wunder, dass sich Mayer fast alle Unterschiede zwischen der deutschen und der französischen Verfassungsentwickelung verflüchtigen, mit Ausnahme derer, die auf thatsächliche Ursachen zurückgehen, wie etwa darauf, dass das deutsche Königthum als Erbe der karolingischen Macht in die Geschichte eintrat, während das französische anfänglich beinahe nur auf die Machtmittel des Herzogthums in Francien sich stützen konnte, oder darauf, dass Frankreich der für Deutschland so unheilvolle Dynastienwechsel erspart blieb ${ }^{1}$ ). Kein Wunder auch, dass Mayer im Gegensatz zu den Bisherigen, die lediglich von den Nachrichten über Deutschland oder lediglich von denen über Frankreich ausgingen ${ }^{2}$ ) und eine deutsche oder eine französische Verfassungsgeschichte schrieben, dazu gekommen ist, uns eine deutsche un d französische Verfassungsgeschichte zu schenken. Ich bin weit davon entfernt, den Nutzen dieses Unternehmens zu bestreiten. Ich sehe ihn aber lediglich darin, dass die Vergleichung, ohne die es natürlich auch bei den Frühern nicht abging - wer wäre bei der Lückenhaftigkeit der Quellen lediglich mit deutschem oder französischem Material ausgekommen! nun thatkräftiger und weniger willkürlich durchgeführt ist, sodass wir besser im Stande sind, dasjenige, was sich aus directen und zeitgenössischen Quellen des einen oder andern Landes ergibt, zu kontrolliren und zu ergänzen. Denn dazu reicht im Grunde dies Rückschlussverfahren allein voll aus.

Doch Mayer hat es nun einmal in erster Linie, nicht bloss subsidiär angewendet. So viel ist klar, dass dabei, wenigstens ohne weiteres, eine Verfassungsgeschichte selbst nicht heraus kommen konnte. In der That erhebt sich sein Buch nirgends zur Darstellung; es enthält lediglich systematische Untersuchungen zur Verfassungsgeschichte. Und zwar systematische Untersuchungen über die Grundlagen und

1) II S. 404 ff., 414 f. $-{ }^{2}$ ) I S. VII, 
die Vorgeschichte der beiden Verfassungen; seine Ergebnisse zielen durchaus auf den Unterbau ab, in ihrem fast grösseren und wichtigeren Theile sogar auf den fränkischen und vorfränkischen, sie bringen in letzter Linie eine nationale Analyse des gesammten Stoffes. Nun hat aber Mayer eine Verfassungsgeschichte der nachfränkischen Zeit schreiben wollen und darum die fränkischen und vorfränkischen Quellen nur nebenbei benutzt. Was ergibt sich hieraus? Nicht mehr und nicht weniger als das, dass sein Werk wenigstens z. Th. auf einen Versuch hinausläuft, Aufschlüsse über die fränkischen und vorfränkischen Verfassungsverhältnisse aus nachfränkischen Quellen und nur aus ihnen zu gewinnen ${ }^{1}$ ). Man vergegenwärtige sich, was das heisst. Es ist, als ob jemand das Wesen eines Verstorbenen, der reichliche Selbstaufzeichnungen hinterlassen hat, und über den auch zahlreiche Zeugnisse von Zeitgenossen erhalten sind, aus diesen zu ergründen verschmähte, um es aus dem Charakter und der Art zweier Söhne, die jener hinterliess, durch Vergleichung herauszuarbeiten, wobei er natürlich diese, wenn auch nicht nur um ihrer selbst willen, mit zu zeichnen sich veranlasst sieht. Doch ich will hierbei nicht verweilen. Nur das sei nachdrücklich hervorgehoben, dass das geschilderte Verfahren Mayer zu einer sehr erheblichen Ueberschreitung der Baulinie in der Lothrichtung veranlasst hat. Sein Werk ist nicht ausschliesslich eine deutsehe und französische, es ist gerade so gut oder gerade so wenig eine fränkische und Urverfassungsgeschichte.

Besser gerichtet ist der Bau in der Horizontalen. Die Richtschnur bildete hier der Gegensatz von ö ffentlichem Recht und Herrschaft. Nach gemeinem Wortverstand wäre das freilich gar kein Gegensatz. Vielmehr wäre dem öffentlichen das private Recht, der Herrschaft die Genossenschaft gegenüberzustellen. Aber Mayer versteht die beiden

1) Vgl. dazu z. B. I S. 434: ${ }_{n}$ Es ist bezeichnend für das zähe Leben der Rechtskörper in dieser Zeit ruhigen Vegetirens, dass gerade die nachfränkischen Quellen ganz überraschende Blicke in die Struktur der Hundertschaft thun lassen und viel mehr enthüllen als die dürftigen Notizen aus fränkischer Zeit". 
Ausdrücke eben in einem besondern Sinne. Oeffentliches Recht ist ihm ,jede Form der Unterthänigkeit oder Herrschaft, welche von einem privaten Recht an der Person und dem Haus des Beherrschten unabhängig ist" ${ }^{1}$ ), eine „öffentliche Hoheit, die sich im Reich und den einzelnen Gerichtssprengeln lokalisirt“" ${ }^{2}$ ). Mit Herrschaft aber bezeichnet er jede "Gewalt privatrechtlichen Ursprungs, insbesondere das Recht des Herren über seine Unfreien und über die freien Genossen seines Hauses und seiner Wirthschaft, die Gewalt, die sich im Hofe und den Gütern der Herren lokalisirt" "3). Nun versteht man, was die Unterscheidung will. Herrschaft ist das, was man sonst ${ }^{4}$ ) wohl als Privatherrschaft bezeichnet. Mayer vermeidet aber den Ausdruck ${ }^{5}$ ), weil in der öffentlichrechtlichen Sphäre der Privatherrschaft nicht bloss eine öffentliche Herrschaft sondern vor Allem die öffentliche Genossenschaft gegenübersteht. Aus dem letztern Grunde, und weil die Herrschaft bald zu einer herrschaftlichen Genossenschaft führt, kann er den ihm vorschwebenden Gegensatz auch nicht mit Genossenschaft einerseits und Herrschaft andererseits ausdrücken. Und noch weniger verwendbar wäre die Gegenüberstellung von öffentlichem und privatem Recht. Denn das private Recht als solches kann für die Verfassungsgeschichte überhaupt nicht in Betracht kommen sondern nur das private Recht, auf das sich im Mittelalter darüber hinausgehende Befugnisse aufbauten. Ferner sind privatrechtliche Triebkräfte auch ausserhalb der Herrschaft wirksam gewesen; man lese z. B. was Mayer über das Erblichwerden und die Allodification der Centgrafschaft beibringt ${ }^{6}$ ). Vor Allem fehlte jener Zeit die Einsicht in den uns so geläufigen Gegensatz oder doch das klare Bewusstsein davon. Eben darum kann man auch der Mayerschen Unterscheidung nicht vorwerfen, dass sie nicht reinlich genug sei. Gerade die gewisse Unklarheit, die ihr zweifellos anklebt, lässt sie als dem Stil des mittelalterlichen Verfassungsbaues gerecht erscheinen. Jedenfalls für die nachfränkische Zeit, während es für die

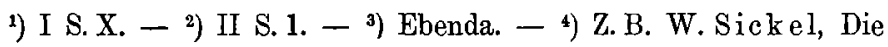
Privatherrschaften im fränkischen Reiche, Westdeutsche Zeitschr. XV 1896, XVI 1897. - 5) Vgl. jedoch I S. IX: kirchliche Privatherrschaften, und II S, 401: Recht der Privatherrschaft. - ${ }^{6}$ ) I S, $447 \mathrm{ff}$. 
ältere dahingestellt bleiben mag, ob auch in ihr die beiden Begriffe als einfachste Einheiten erscheinen, oder ob eine energische historische Analyse zu noch einfacheren führen würde. Auch will ich nicht sagen, dass die Bezeichnung die glücklichste sei, die man dafür finden könnte; augenblicklich sehe ich mich allerdings ausser Stande, eine bessere in Vorschlag zu bringen. Und ich will nicht behaupten, dass die Zutheilung zur einen oder andern Seite, die Mayer vorgenommen hat, immer das Richtige treffe, dass z. B. alle Hofbeamten ohne weiteres für die Herrschaft in Anspruch genommen werden dürften. Oeffentliche Gewalt und herrschaftliche Gewalt beeinflussten sich nicht nur gegenseitig, vielmehr griffen sie, wie Mayer selbst betont ${ }^{1}$ ), auch vielfach in einander über, sodass es manchmal schwer hält, darnach zu scheiden und die Zutheilung zweifelhaft bleiben muss. Aber die Empfindung habe ich bei meinen eigenen Arbeiten immer gehabt und Mayers Buch bestärkt mich darin: dieser Gegensatz hat in der ältern Verfassungsgeschichte wirklich entscheidend gewaltet. Und er war eine Realität; wir schaffen ihn nicht künstlich und legen ihn nicht von uns aus hinein.

Der Gegensatz von öffentlichem Recht und Herrschaft durchzieht den ganzen Stoff der älteren Verfassungsgeschichte; er greift durch, höchstens mit dem Unterschied, dass in den älteren Schichten das öffentliche Recht überwiegt, in den jüngeren die Herrschaft, was aber gerade glücklich das andere Verfahren ergänzen hilft, das nur auf die älteren Schichten als solche führt, aber deren Datirung und Bestimmung für sich allein nicht immer ermöglicht. Darum hat Mayer den Gegensatz von öffentlicher und herrschaftlicher Gewalt zum Eintheilungsprincip gemacht und mit dessen Hülfe den Stoff so gegliedert, dass er in einem ersten Theile das öffentliche Recht behandelt, in einem zweiten die Herrschaft und in einem dritten die höchste Gewalt, die aus Bestandtheilen beider sich zusammensetzt und beide zusammenfasst. Wir halten uns jedoch im Folgenden nicht an diese Anordnung, sondern greifen einige besonders wichtige Ergebnisse heraus, um die übrigen um diese zu gruppiren.

1) II S, 2 . 
II.

Der Anfang sei gemacht mit dem Satze Mayers, dass der gemeine Freie von jeher und als solcher zinspflichtig war ${ }^{1}$ ). Das widerspricht durchaus der hergebrachten Anschauung, wonach erst in karolingischer und in nachfränkischer Zeit die Unfähigkeit, den Kriegsdienst den gesteigerten Anforderungen gemäfs zu thun, grosse Massen von Freien den Grafen und anderen Senioren gegenüber schatzoder schosspflichtig machte, die dann von dem Ertrag der Steuer Ersatzleute für die Unfähigen zum Aufgebot stellten ${ }^{2}$ ). Im Gegensatz hierzu rückt Mayer die Zinspflicht in die germanische Zeit hinauf, und lässt er von vornherein alle gemeinen Freien von ihr betroffen werden. Nach ihm hatten nämlich die herrschenden Geschlechter in der Hundertschaft, auf die wir im nächsten Abschnitt zurück kommen werden, die Verfügung über die Mark, insbesondere über den Wald ${ }^{3}$ ). Für die Erlaubniss zur Ansiedelung und Rodung musste daher von den geringeren Geschlechtern den herrschenden oder ibrem Führer und Häuptling eine Abgabe entrichtet werden ${ }^{4}$ ), die ein Kopfzins ${ }^{5}$ ) und im Gegensatz zu der als ursprüngliche Gerichtssteuer zu deutenden, unbestimmten Jahrbede $^{6}$ ), genau bestimmt war ${ }^{7}$ ). Schon zur Zeit der Reichsgründung erschien dieser Zins so sehr als Freienabgabe, dass er auch von den Freien der eroberten Gebiete, insbesondere Südfrankreichs erhoben wurde ${ }^{8}$ ). Natürlich bezog

1) I S. 11-47. - 2) Vgl. statt Anderer Schrö der, Rechtsgeschichte 3. Aufl. S. $153 \mathrm{f}$., $445 \mathrm{f}$. Ueber ältere, z. Th. aus römischer Zeit stammende Abgaben, welche die Freien aber nicht als solche und nicht überall trafen, siehe ebenda S. $190 \mathrm{ff.}-{ }^{3}$ ) I S. $410 \mathrm{ff.}-{ }^{4}$ ) I S. 44, $421 \mathrm{f}$. 5) I S. 32. - ") I S. 11-16. - 7) Für das fränkische Hauptland ergibt sich wie für Alamannien ein Königszins von 4 Denar, für die belgischen Gebiete, den Niederrhein und Friesland ein solcher von 2 Denar, in Baiern von 5, ohne dass ein Grund für diese Verschiedenheit zu ermitteln wäre. I S. 31. - 8) I S. 18, 20, 22. Durch Unterwerfung unter den Königszins erwirbt man die Staatsangehörigkeit I S. 32. Freilich wurde die Steuer auch von den unfreien, aber ständigen Inhabern abhängiger Bauernhöfe exhoben. Gerade darum heisst der Besitzer des mansus servilis fiscalinus, von fiscus, Abgabe (die von Brunner, Rechtsgeschichte I S. 237 und Schröder a. a. 0. S. 217 vertretene Erklärung der fiscalini als einer aus der Zusammenfassung 
man ihn jetzt auf den König ${ }^{1}$ ); die Capitularien kennen ihn als Königszins, als census regius ${ }^{2}$ ). In nachfränkischer Zeit bestand er in allen Reichstheilen fort, theils unter dem alten Namen, theils als Königssteuer, Königsschuld, Schatz, Grafenschatz, Grafenzins, Grafenschuld, Vogtsteuer oder Vogtrecht. Person und Eigenthum des Steuerpflichtigen, des Bargilden ${ }^{3}$ ), wurden nunmehr durch ihn gemindert ${ }^{4}$ ): Schenkung ${ }^{5}$ ) der Abgabe galt als Schenkung des Pflichtigen ${ }^{6}$ ), und nur gegen einen an die Obrigkeit zu entrichtenden Handlohn kann das mitbelastete Gut veräussert werden ${ }^{7}$ ). So bildet sich die Vorstellung heraus, dass gar nicht der Steuerbelastete, sondern der Steuerempfänger das Eigenthum habe, d. h. also für die Regel die Grafen, die, wie schon die oben angeführten späteren Benennungen lehren, den Königszins

der servi casati und der Hörigen des Königs entstandenen Classe verwirft Mayer). Diese Mithineinziehung der unfreien mansionarii sei aber nicht germanisch, gehe vielmehr auf römisches Recht zurück I S. $42 \mathrm{ff}$, II S. 13 mit N. 37 f., S. 64, 71.

1) I S. 424. $-{ }^{2}$ ) I S. 22. Eine Abgabe unterworfener Völker war er nach Mayer nicht, da ihn auch die Nichadeligen des herrschenden Stammes zahlten I S. $37 \mathrm{f}$. Tributpflichtige Unterworfene sieht Mayer dagegen in den Barschalken des bairischen Rechtes und überall in den Liten I S. 47-52. - ${ }^{3}$ ) I S. 41, 410, 423. Auch Płleghafter, homo advocaticius. Das Hinderniss des Reichsweisthums von 1282 , das deutlich homines advocaticii und Freie, die Bauern, also durchaus keine Vornehmen sind, unterscheidet, glaubt Mayer S. 19 N. 23 dadurch beseitigen zu können, dass er es nur auf Berg bezieht, von woher die Frage kam, und wo es a usnahmsweise Freie gegeben habe, die keine Steuern zahlten, ohne Ritter oder Kleriker zu sein. Vgl. I S. 37. 4) Das steuerpflichtige Eigen heisst torslaht (torfaht) eigen, also Dörflereigen. Die herkömmliche Deutung von durchschlächtigem Eigen als vollkommenes Eigen ist nach Mayer I S. 40 mit N. 113 das gerade Gegentheil von richtig. - ${ }^{5}$ ) Durch die also der Steueranspruch auch einem nicht die öffentliche Gewalt innehabenden Herrn einer privaten, besonders einer kirchlichen Herrschaft zugewendet werden konnte. I S. 18. - ') I S. 44. - 7) I S. 22 ff. Nach dem auf älteres Recht zurückgehenden c. 28 des edictum Pistense dürfen solche, die dem census regius unterworfen sind, nur dann an die Kirchen sich ergeben, wenn der census - von der Kirche - fortbezahlt wird. Doch darf diese obrigkeitliche Genehmigung zu solcher Hingabe, die im Laufe der Zeit zu einem Recht auf Handlohn wird, nicht als Wurzel des Friedewirkens bei der Grundstücksübereigmung angesehen werden, wenigstens nicht überall. 
gleich so manchem andern königlichen Rechte an sich gebracht hatten. Das Freienland wird zur terra comitalis, in Deutschland wie in Frankreich bildet sich der Satz heraus: Nulle terre sans seigneur, d. h. in der Grafschaft gibt es für den Gemeinfreien grundsätzlich kein Allod, und der Inhaber der Grafengewalt ist nun Landesherr ${ }^{\mathbf{1}}$ ).

Es liegt auf der Hand, was für ein gänzlich verändertes Gesicht die Geschichte des so überaus wichtigen Standes der Gemeinfreien bekommen würde, wenn Mayers Auffassung aller jener zahlreichen und vielgestaltigen Freienabgaben der späteren Zeit als einer einheitlichen, in die germanische Zeit zurückreichenden Steuer sich als richtig erweisen würde. Inzwischen ist ihr freilich in Philipp Heck ${ }^{2}$ ) ein Gegner entstanden, der sie von einer Seite her angreift, von der man es am allerwenigsten erwartet hätte, nämlich dadurch, dass er im Gegensatz zu Mayer, aber auch zu der bisher herrschenden Ansicht die Biergelden ${ }^{3}$ ) nicht als steuerbelastete freie Leute deutet, sondern - völlig überraschend - als Städter.

Ausgehend von den friesischen Quellen, aus denen, wie er glaubt, mit Gewissheit erhellt, dass berielda nicht einen Stand bezeichnet, sondern den Angehörigen eines Gerichtsbezirkes ${ }^{4}$ ), sucht er, nachdem er auch die bargildi der Capitularien ${ }^{5}$ ) und die bergildi einiger Osnabrücker Urkunden des 11. Jahrhunderts ${ }^{6}$ ) als Gerichtsgenossen erklärt hat, für die bekannten, zweifellos unechten Stellen der Würzburger Immunitätsbriefe von ca. 962, 996, 1018, 1032 und 1049, die von parochi berichten, quos bargildon dicunt, einen Bedeutungswandel von dieser allgemeineren Grundbedeutung zu der speziellern von Bewohnern der eximirten städtischen Gerichtsbezirke darzuthun ${ }^{7}$ ), um schliesslich eingehend auszuführen, dass, wie einmal im Rechtsbuch nach Distinctionen ${ }^{8}$ ), so immer im Sachsen-

1) I S. 44 f., II S. 373, 403. - 2) In der oben S. 115 A. 1 citirten Abhandlung. $-{ }^{8}$ ) bargildus entsprechend baro minofledus und ähnlichen Bildungen: der freie Zahler oder der zahlende Freie. - ${ }^{4}$ ) S. 5-9. Bereits Theod or Lindner, Die Veme, Münster und Paderborn, 1888 S. 170 N. 1 hatte das Wort Bargilde als Gerichtsgenosse gedeutet. - 5) S. 10-12. 5) S. 12-15. - 7) S. 15-27. - 8) S. 27-29. Schon Stobbe hatte in der Ztschr. f. deutsch. Recht XV. S. 350 A. 103 für diese Stelle die 
spiegel ${ }^{1}$ ), Biergelde die Bezeichnung für Städter sei. Die Abhandlung ist mit dem Scharfsinn und mit der frischen Energie geschrieben, die wir uns an Hecks Arbeiten gewohnt sind. Sie besticht den Leser auch durch die saubere $\mathbf{A b}$ grenzung des Untersuchungsstoffes sowie durch ihre wohlthuende Knappheit und Praecision. Aber sie schiesst, vielleicht gerade in Folge zu scharfer Isolirung des Themas, in den wesentlichen Punkten neben vorbei und thut den Quellen Gewalt an. Die Beweisführung Hecks hat mich in keinem Theile zu überzeugen vermocht.

Schon darin fehlt er, dass er die Ansicht, die er bekämpft, unrichtig formulirt: nicht Zinszahler schlechthin, sondern schatzpflichtige Freie sah man bisher in den Biergelden. Also hätte Heck seinen Gegnern vor Allem nachzuweisen gehabt, dass die Quellen unter Biergelden keinesfalls eine besondere Art von Freien verstanden, ein Nachweis, der freilich angesichts der unzweideutigen Bestimmtheit einer ganzen Reihe von Quellenaussprüchen von den Capitularien an ${ }^{2}$ ) bis herab auf den Sachsenspiegel ${ }^{3}$ ) einfach nicht zu erbringen ist.

Gleichung biergelde $=$ burger zugegeben. Man legte aber, trotzdem schon ältere Schriftsteller die Biergelden als Stadtbürger erklärt hatten (Heck S. 30), darauf kein Gewicht, da man Grund zu der Annahme zu haben glaubte, es sei dieser wie den späteren Quellen überhaupt der wahre Sinn von Biergelde nicht mehr bekannt gewesen. Auch Heck sieht sich übrigens S. $61 \mathrm{ff}$. zu der Annahme genöthigt, dass die meisten Quellen des späteren Sachsenrechtes das Wort nicht mehr verstehen.

1) S. 29 ff. - 2) Capit. 86 (I S. 185) c. 4: Leute, die von Alters her servi waren, wollen se ingenuare et facere se bargildiones. Es sei nicht wahrscheinlich, dass solche sich eine zinspflichtige Freiheit haben erschleichen wollen, meint Heck S. 12. Ich meine umgekehrt, ein Erschleichen eines andern als des nächstliegenden, d. h. untersten Freiengrades sei bei den damaligen Verhältnissen geradezu ausgeschlossen gewesen. Capit. 162 (I S. 325) c. 3: Ceteri ... liberi homines, quos vocant bharigildi. Den Gegensatz bilden die Freien, die Vassallen sind. Gefälschtes Würzburger Immunitätsprivileg Ottos I. (bei Heck S. 15): servos vel accolas sive alios quoslibet liberos homines parochos, quos bargildon dicunt, nec non et Saxones ... quique se vel sua novalia... tradidissent und später homines, servos, Sclavos, accolas Saxones ... nec non etiam parochos, quos bargildon dicunt, seu alios liberos homines. Echte Urkunde Friedrichs I. von 1168 für dasselbe Stift (ebenda S. 17): liberis hominibus, qui vulgo Bargildi vocantur. $-{ }^{3}$ ) Ldr. I 2 $\S 1 \mathrm{ff}$ : Vriheit de is aver drierhande: scepenbare lüde ... plechhaften, 
Nicht besser steht es mit den positiven Ausführungen Hecks. Die Grundbedeutung Gerichtsgenosse ist eitel Trug und Schein. Natürlich lässt sich, wenn die Rede ist von den Biergelden eines Richters, etwa des Grafen, oder eines Urtheilers oder sonst Jemandes, der über oder für einen Bezirk obrigkeitliche Gewalt übt, daraus die Zugehörigkeit zu dem Amtsbezirk herauslesen. Aber dies liegt, was den Ausdruck anbelangt, an dem Genetiv ${ }^{1}$ ) oder an dem Pronomen ${ }^{2}$ ) oder in der ganzen Wendung ${ }^{3}$ ), und was die Sache angeht, an der Gestaltung der mittelalterlichen Gerichtsverhältnisse, welche den Gerichtsunterworfenen als einen Angehörigen des Gerichtsherrn erscheinen liess, nie und nimmer aber im Wort oder Begriff Biergelde. Man mache nur einmal die Probe, setze in den Quellen für bargildi oder Biergelden liberi bezw. Freie ein und sehe zu, ob man mit Hecks Beweisführung nicht auch dafür auf die Grundbedeutung Gerichtsgenosse kommt. Aber die Biergilde der Hunsigoer Willkür $\left.{ }^{4}\right)$ ? Nun, wenn Heck auch die süddeutschen Quellen und Verhältnisse berücksichtigt hätte, so würde er auf den

welche zweifellos mit den biergelden identisch sind, was auch $\mathrm{Heck}$ S. 29 annimmt, lantseten, III $45 \S 4 \mathrm{ff}$.: Die biergelden unde plechhaften heten .... mit $\S 6$ : Andre vri lüde sint lantseten.

2) Capit. 273 (II S. 324) c. 32: ipse (comes) sic mallum suum teneat, ut barigildi eius et advocati, qui in aliis comitatibus rationes habent, ad suum mallum occurrere possint. Hier sei die Beziehung des Wortes eine rein locale, meint Heck S. 11. „Die Nothwendigkeit, an sein Gericht zu kommen, wird nicht durch rationes (Gerichtsangelegenheiten) motivirt, kann also nur auf Be zirksangehörigkeit beruhen". Ich sage: auf Freiheit und Bezirksangehörigkeit, von denen die letztere durch das eius ausgedrückt ist, während die erstere in dem Begriffe barigildi liegt. - ${ }^{2}$ ) Z. B. sin berielda, mine berieldan, hoere biergilde in den friesischen Quellen oder Ssp. III 64 §: Deme scultheiten ..... sine biergelden. $-{ }^{3}$ ) Wie etwa: omnes illi biergeldon de illo placito, omnes biergeldon, qui in comitatu eoru $\mathrm{m}$ (Alfger et Hemmic) manent, omnes bergildi ad predictum placitu m pertinentes in den Osnabrücker Urkunden oder: comites de liberis hominibus, qui vulgo Bargildi vocantur, in comitiis habitantibus statutam iusticiam recipere debent in der echten Würzburger Urkunde von 1168. Aehnlich heisst es z. B. in dem bekannten habsburgischen Theilungsvertrage von 1238 (Kopp, Geschichtsblätter, Lucern 1854, S. 54): die vrien lüte ze Ergouwe. - ${ }^{4}$ ) Bei Heck S. 5: End die rechteren of hoer medezyden sullen niemant in hoere biergild e overherig keeden.

Zeitschrift für Rechtsgeschichte. XXI. Germ. Abth. 
formell ${ }^{1}$ ) ganz entsprechenden Ausdruck Freiamt ${ }^{2}$ ) gestossen sein. "Die Richter oder ihre Beisitzer sollen Niemanden in ihrem Freiamt (d. h. von den Freien bezw. Freiengütern, die zum Freiengerichte gehören ${ }^{3}$ )) für ungehorsam erklären", könnte es ganz wohl auch in einer alemannischen oder schweizerischen Quelle heissen. Wer wollte aber deshalb behaupten, der Begriff Freiamt (Freienschaft ${ }^{4}$ )) erschöpfe sich in der Gerichtsgenossenschaft, oder es sei Gerichtsgenosse der ursprüngliche und eigentliche Sinn von Frei! Offenbar ist Heck durch die drei, von ihm ja auch an die Spitze gestellten friesischen Zeugnisse auf seine Biergeldentheorie gekommen. Allein es geht nicht an, dass man sich das Wesen eines so oft und so gut bezeugten Begriffs aus einigen künstlich isolirten Belegen späterer Zeit, die obendrein nicht einmal ex professo der Sache Erwähnung thun, zurechtlegt, um dann die so gewonnene Erklärung in die übrigen, theils viel älteren, theils viel deutlicheren, und jedenfalls viel wichtigeren Stellen hineinzutragen. Beruht somit schon der neugewonnene Grundbegriff der Bezeichnung Biergelde, wie mir scheint, auf einem Missverständnisse, so brauche ich mich bei dem daraus abgeleiteten: Angehöriger eines städtischen Gerichtsbezirkes gar nicht weiter aufzuhalten. Dies um so weniger, als die Beweisführung, durch welche für die Würzburger Immunitätsbriefe die Specialisirung der bargildi von Gerichtsgenossen überhaupt zu Städtern dargethan werden sollte, keineswegs zwingend ist ${ }^{5}$ ), wie auch

1) Ich bitte zu beachten, dass ich damit nicht eine sachliche Uebereinstimmung zwischen Biergelde und Freiamt behaupten will. $\left.{ }^{2}\right)$ Friedrich v. Wyss, Die freien Bauern, Freiämter, Freigerichte und die Vogteien der Ostschweiz im späteren Mittelalter, neu abgedruckt in desselben Abhandlungen zur Geschichte des schweizerischen öffentlichen Rechts, Zürich 1892 S. 161 ff., eine Untersuchung, die beim Studium des mittelalterlichen Ständerechts immer wieder als unentbehrlicher und aussergewöhnlich zuverlässiger Führer sich erweist. Siehe auch Andreas Heusler, Institutionen I S. 169 f., II S. 97. - ${ }^{3}$ ) v. Wyss a. a. O. S. 191 f., 205 f., 267 f. - $\left.{ }^{4}\right)$ Vrye gnozami im Habsburgischen Urbar, heransg. von Maag I Basel 1894 S. 179 f. - 5) Zunächst habe ich mich nicht davon überzeugen können, dass es sich in der Würzburger Urkunde von 1168 nicht um den Vorbehalt eines Zinses, sondern einer Gerichtsbarkeit handelt. Warum soll der Kaiser nicht haben sagen wollen: der Freienzins der ja ursprünglich durchaus eine öffent- 
im Sachsenspiegel diejenigen Stellen, welche - man denke etwa an die Zeugnisse über die Wahl des Fronboten aus den Biergelden ${ }^{1}$ ) - der neuen Erklärung in erster Linie

liche Abgabe ist) fällt nicht mit in die Immunität, verbleibt vielmehr den (durch die Immunität und die damit verbundene Entziehung der Gerichtsbarkeit ohnehin geschädigten) Grafen? Für die Deutung des statutam iusticiam recipere auf einen Zinsbezug, die schon an sich am nächsten liegt, gibt trotz Heck S. 21 die Urkunde von 1206, wie mir scheint, unbedingt den Ausschlag. Sollten nicht etwa die Fälschungen gerade deswegen vorgenommen worden sein, damit der unbequeme Vorbehalt von Urkunden wie der von 1168 bei späteren Privilegirungen wegfallen konnte? Aber auch parochus ohne weiteres für parochianus zu nehmen und einfach als Uebersetzung von Gerichtsgenosse zu erklären, wie das Heck S. 18 thut, halte ich für bedenklich. Mir sind überhaupt diese parochi höchst verdächtig. Parochus kommt nach meiner Kenntniss selbst in den kirchlichen Quellen der älteren Zeit nicht vor, nicht einmal für den Pfarrer, der stets parochianus oder parochialis oder auch wohl parochinus (presbyter) heisst, wie denn auch Ducange keinen einzigen Beleg für parochus gibt. Sollte etwa der zweifellos gelehrte Fälscher, weil er das deutsche Wort nicht mehr verstand, dabei mit dem auch mittelalterlich-griechischen $\pi \dot{\alpha} \rho \circ \iota_{x} \iota=$ Hintersassen sich geholfen und so den accolae Saxones die paro(e)ci quos biergeldon dicunt zur Seite gestellt haben? Sodann halte ich es für unvereinbar mit der Syntax selbst der mittelalterlichen Urkundensprache, wenn aus dem Passus: homines, servos, Sclavos, accolas Saxones, quos Northelbinga dicunt, nec non etiam parochos, quos bargildon dicunt, seu alios liberos homines, undecunque nati sint vel quocunque iure debeant vivere, qui se vel sua alodia in ius et potestatem praefatae aecclesiae quomodolibet mancipando subdiderunt, der Relativsatz undecunque - vivere, der doch offenbar zu den zuletzt und früher genannten liberi, wenn nicht zu allen vorgenannten homines gehört, von Heck S. 24 zerlegt und in seiner ersten Hälfte ausschliesslich auf die Saxones, in seiner zweiten ausschliesslich auf die bargildi bezogen wird, wodurch diese dann zu Leuten werden, "die nach einem besonderen Rechte leben". Und endlich ist auch nach Hecks Ausführungen nicht einzusehen, weshalb die bargildi, selbst wenn man sie als Gerichtsgenossen mit besonderem Rechte gelten lassen wollte, gerade Stadtgerichtsgenossen sein müssten. Vielmehr weist die echte Urkunde von 1168 mit ihrem oben S. 129 A. 3 abgedruckten Passus zum Mindesten in erster Linie auf das Land; denn es ist darin von comites und comitia schlechthin die Rede, und auch Heck wird nicht leugnen wollen, dass selbst in städtereichen Gebieten die grosse Mehrzahl der Grafschaften ländlich gewesen ist.

1) Ssp. Ldrs. I 2 §, III $45 \S 5$, III $61 \S 3$. Was Heck S. 59 dazu bemerkt, kanm man kaum als einen schwachen Versuch einer Lösung des 
widerstreben ${ }^{1}$ ), von Heck nicht haben aus dem Wege geräumt werden können. Wie immer auch die künftige Forschung über Mayers Freientheorie entscheiden wird, das scheint mir jetzt schon sicher, dass Hecks Lehre von den Biergelden trotz alles Geistes und Geschickes, mit dem sie ihr Urheber uns vorgetragen hat, in keiner Weise jene Theorie zu erschüttern im Stande sein wird ${ }^{2}$ ).

\section{III.}

Aber auch über das Wesen und die Geschichte des ältesten, auf Geburt beruhenden Adels entwickelt Mayer eigene, zum grossen Theile ganz neue Gedanken.

Widerspruchs zu seiner Theorie gelten lassen. Vgl. auch Christian Eckert, Der Fronbote im Mittelalter, Leipzig 1897, S. $14 \mathrm{ff}$., $21 \mathrm{f}$.

1) Hieher gehören neben Ssp. Ldrs. I $2 \S 3$ über die Pflicht, alle 6 Wochen zum Ding zu erscheinen, und III 45 über das Wergeld namentlich III 80, wo das für Biergeldenland im Gegensatz zur Fahrhabe geltende besondere Anfallsrecht bei Erblosigkeit gerade im Zusammenhange mit der Schatzpflicht sich weit besser als nach Heck S. 47 f., 53 erklärt, und weiter III $61 \S 2$, für welche Stelle Heck S. 49 nur mit der Annahme eines Irrthums oder mangelhafter Information Eikes sich zu helfen weiss. Endlich steht Alles, was Heck S. 50 ff. über das Sendgericht des Dompropstes ausführt, durchaus im Widerspruche zu den Quellen, insbesondere den Urkunden, die nichts davon wissen, dass der Dompropst der Sendrichter lediglich oder auch nur in erster Linie der Städter war. Es kann jetzt für diese Frage einfach auf die gründlichen Untersuchungen von Nikolaus Hilling, Die bischöfliche Banngewalt, das Archipresbyterat und das Archidiakonat in den sächsischen Bisthümern im Archiv f. kath. Kirchenrecht LXXX 1900 S. 80 ff., 323 ff., 443 ff. verwiesen werden, die schon in den bisher erschienenen Theilen Material genug an die Hand geben. Eine erschöpfende Widerlegung Hecks liegt selbstverständlich ausserhalb des Planes dieser Studie. Darum muss ich es mir versagen, an dieser Stelle auf eine Erörterung der interessanten Ausführungen über Ssp. Ldrs. I 71, I 58 \$2 und besonders III $52 \$ 2$ einzutreten. Man kann dabei Heck z. Th. zustimmen, ohne darum in den Biergelden Stadtbürger sehen zu müssen. Von der Walkenrieder Urkunde aber gesteht Heck S. $56 \mathrm{f}$. selbst, dass ganz wohl eine andere Deutung als die seinige möglich ist; ich meine sogar, sie könne bei unbefangener Betrachtung gar nicht anders als von einem Streit um Steueransprüche verstanden werden. Siehe auch Mayer I S. 399, N. 60. - $\left.{ }^{2}\right)$ H e ck bezeichnet übrigens seine Ergebnisse, wenigstens soweit sie den Ssp. betreffen, selbst nur als vorläufige, die Anregungen zu weiterer Untersuchung geben sollen. 
Nach ihm geht nämlich der älteste Adel zurück auf die hundert tonangebenden Familien der Waldmark und der Hundertschaft ${ }^{1}$ ). Deren Angehörige waren die „Rechtler (“ 2 ), denen die Holz- und Moorberechtigungen ${ }^{3}$ ), dauernd hundert an $\mathrm{Zahl}^{4}$ ), zustanden ${ }^{5}$ ). Sie gaben in der Hundertschaft und in der Völkerschaftsversammlung die Entscheidung; aus ihnen wurde der Hundertschaftsvorsteher gewählt ${ }^{6}$ ); in ihrem Namen wurde von diesem durch Rodungs- und Ansiedelungsprivilegien über die Mark verfügt und der Zins von den gemeinen Freien erhoben ${ }^{7}$ ); sie traten auch in Gemeinde, Hundertschaft und Völker(Graf)schaft zuerst als Urtheiler oder Schöffen auf ${ }^{8}$ ). Dabei entsprang ihr Vorrang offenbar dem Umstande, dass diese Familien vor den anderen zum Vaterrecht und zur Einzelerbfolge übergegangen waren ${ }^{9}$ ). Früher als die gemeinen Freien hatten die Vornehmen, weil die Reichen, Frauen gekauft oder geraubt, um mit ihnen und den Kindern im eigenen Haushalte dauernd zusammenzuleben, indess die grosse Masse noch in Heerden von Verwandten von derWeiberseite her unter dem avunculus hauste ${ }^{10}$ ). Und früher als die anderen brachten es diese vornehmen Freien zu einem Stammhaus, einer Heimat, einem Hant-

1) I S. $421 \mathrm{ff}$. Es finden sich also bei Mayer gewisse Anklänge an die Ansichten, die in letzter Zeit August Meitzen, Siedelung und Agrarwesen der Westgermanen und Ostgermanen, Berlin 1895, I S. $137 \mathrm{ff}$., Richard Hildebrand, Recht und Sitte auf den verschiedenen Culturstufen, Jena 1896, S. 60 ff. und Werner Wittich, Die Grundherrschaft in Nordwestdeutschland, Leipzig 1896, Anlagen S. 108* ff., freilich jeder in anderer Weise vertreten haben (siehe auch in dieser Zeitschr. XIX 1898 S. $169 \mathrm{f}$.). Ich kamn aber nicht finden, dass die Theorie von den "Reichen oder Vornehmen" durch diese mehr nur zufällige Uebereinstimmung an Wahrscheinlichkeit gewinnt. - 2) I S.417. 3) Warschaften, womit Mayer I S. 412 kurzer Hand das watriscapium der Formeln und altfränkischen Urkunden zusammenbringt! - 4) I S. 411, 412 f. - 5) Eben darauf soll die Bezeichnung homines potestativi oder potestatem habentes gehen, die in den bairischen Güterverzeichnissen und Urkunden begegnet. I S. 413 . - ') I S. $445 \mathrm{f}$. 7) Siehe oben S. 125 A. 4. - ${ }^{8}$ ) I S. 403, 406, 422. Die centeni comites von Tacitus, Germania c. 12 und die in c. 6 von demselben erwähnten hundert Auserlesenen der gemischten Reiter- und Fusskämpfertruppe, die man sonst wohl sorgfältig auseinanderhält, werden von Mayer I 422 unbedenklich als identisch genommen. - ${ }^{\circ}$ ) I S. $417 \mathrm{ff} .-{ }^{10}$ ) I S. $420,424$. 
gemal, das mit der Markberechtigung ausgestattet war ${ }^{1}$ ), und in das sie den Aeltesten oder den Jüngsten, jedenfalls aber nur einen Einzelnen nachfolgen liessen, während die gemeinen Freien in Nachwirkung der länger bewahrten Gemeinschaft daran festhielten, dass gleichnahe Verwandte zusammen succedirten. Natürlich kam auch im Wergeld die hervorragende Stellung der Vornehmen zum Ausdruck, indem sie mit dem Doppelten oder Dreifachen des gemeinen Freienwergelds gebüsst wurden ${ }^{2}$ ). Aber diese Steigerung entpuppt sich bei näherem Zusehen nicht sowohl als eine etwa nach Analogie des Antrustionenwergelds angemafste Vervielfachung ${ }^{3}$ ) sondern lediglich als eine Errungenschaft. zähen Beharrens beim Alten. Wie sie auch sonst in der weiteren Entwickelung am Alten festhielten ${ }^{4}$ ), so wahrten sie sich beim allgemeinen Uebergange zur neuen Währung für ihre Wergelder und Bussen die Zahlung oder doch die Rechnung in altem Gelde, womit ihre Besserstellung von

1) I S. 421 f.: „Es haben sich die Berechtigungen, die aus der Jäger- und Hirtenzeit ohne intensiven Anbau stammen, auf gewisse Höfe radicirt", „etwa auf die in den ursprünglichen Bifängen belegenen" I S. 416, 417, die dann als Principalhöfe erscheinen im Gegensatze zu den minderen Höfen der Bauern I S. 424. - 2) I S. 430 . -

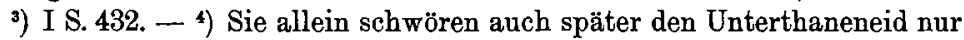
dem König oder dem Grafen, während die geringeren Leute den Eidschwur nicht dem Eidberechtigten persönlich sondern einem Vertreter thun I S. 2 f., S. 4 ff., II S. 166, 174. Wie sie in der Hundertschaft den Ton angaben, so behaupteten sie auch auf den merowingischen Völkerschafts(Grafschafts) versammlungen, insbesondere auf den zum Erlasse von Gesetzen zuständigen provinciellen Märzfeldern, das entscheidende Consensrecht I S. 380 f.; ja auf dem königlichen Märzfelde, das nichts anderes war als die Völkerschafts(Grafschafts)versammlung, bei der sich der König gerade aufhielt (vielleicht wurde gerade zur Vermeidung eines Zusammenfalls mit den Völkerschaftsversammlungen die Reichsversammlung in den Mai verlegt), erschienen ebenfalls die Adeligen des fränkischen Stammes, die alten Hundertschaftsfamilien I S. 381. Weiter behauptet nach Mayer I S. 372 der franc homme sich das Vorrecht, in schweren Sachen und bei Immobiliarstreitigkeiten nur von 6 zu 6 Wochen Recht zu nehmen, wozu man unten sub VI vergleiche. I S. 482: Die Vornehmen halten darauf, dass der Graf dem Gerichte vorsitzt und behaupten so für sich den aus dem Gesichtspunkte des öfentlichen Interesses ergangenen karolingischen Satz, dass Blutgericht nur im Grafending gehalten werden könne. 
selbst gegeben war ${ }^{1}$ ). Gerade darum aber, weil es sich dabei nicht um das Erzeugniss einer allgemeinen gesetzgeberischen Malsregel handelt, sondern um etwas mehr durch die Bemühungen Einzelner Gewordenes, greift das Kriterium des höheren Wergeldes nicht durch ${ }^{2}$ ).

Viel sicherer kennzeichnet die Steuerfreiheit den Adeligen. Nach der Reichsgründung erlangte das, was in der germanischen Hundertschaft nur Ausfluss des Verfügungsrechtes über die Mark und somit bloss mittelbar Adelsvorrecht gewesen war, nämlich die Freiheit voì Rodungs-, später Königszins ${ }^{3}$ ), die Bedeutung eines Standesmerkmals ersten Ranges. Nicht so sehr als homo exercitalis ${ }^{4}$ ) tritt der nobilis

1) I S. 431 ff. Hierin stimmt also Mayer zum Theil mit Hecks Resultaten über das friesisch-sächsische Ständerecht überein, die er im Uebrigen ablehnt. - ${ }^{2}$ ) I S. 426 ff. "Man hat so" - zu Unrecht „allgemein auch die Existenz eines fränkischen Adels bestritten, weil hier wenigstens ursprünglich von einem Adelswergeld nichts zu finden ist". I S. 426. - ${ }^{3}$ ) oben S. 133. - ${ }^{4}$ ) I S. $48 \mathrm{ff} ., 410,414$. Die bekannte Stelle bei Meichelbeck, Historia Frisingensis II S. 320 Nr. 629 von 843, wo ein gewisser Baldrich überträgt talem proprietatem, quam haberet in exercitu (nicht exercitis, wie Ma y e r I S. 49 N. 15 angibt) Baiowariorum in locis nominatis Tannara, Helidkereshusir, Chleninawa, Munninpah wird von Mayer I S. 49 und 414 dahin verstanden, dass exercitus die Bezeichnung einer besonderen Besitzform sei und einen bevorrechteten, d.h. mit Holzberechtigung in der Hundertschaft (exercitus) ausgestatteten Besitz bedeute. Der Fall ist für die Art und Weise, wie Mayer die Quellen interpretirt, charakteristisch, weshalb ich mir nicht versagen kamn, bei ihm ausnahmsweise aus der Rolle des schlichten Berichterstatters herauszutreten. Mit der Hundertschaft und mit Vorrechten in der Hundertschaft hat nämlich die Wendung gar nichts zu thun. In exercitu Baiowariorum ist nur ein anderer Ausdruck für das, was dieselbe Urkunde einige Zeilen früher mit in finibus Baiowariorum sagen will, und wofür andere Freisinger Instrumente jener Zeit in provincia Baiowariorum verwenden. Das Geschäft ist nämlich ausserhalb Baierns, bei der Dungeiche nächst Verdun, abgeschlossen worden. Was man aus der Urkunde für die Verfassungsgeschichte schliessen kann und darf, ist, dass der Stamm oder die Völkerschaft als das Heervolk, das entsprechende Territorium als das Heergebiet erschien. Vgl. in exercitu Asterliudi, in orientali exercitu bei v. Mülverstedt, Regesta archiep. Magdeburg. I 599 S. 251 aus vita Meinwerci c. 52, 69 und secundum ritum Ostersahson herescaph bei Erhard, Regesta hist. Westfaliae, I Cod. dipl. 182 S. 141 von 1113. Man sieht, es ist gegenüber Mayers Quellenerklärungen und Schlüssen die äusserste Vorsicht geboten. 
in fränkischer und nachfränkischer Zeit auf, denn als homo francus. Frank heisst schon früh keineswegs jeder oder gar nur derjenige, der zum herrschenden Frankenstamme gehört ${ }^{1}$ ). Als francus wird vielmehr der von allem, auch vom öffentlichen Zins Freie bezeichnet ${ }^{2}$ ). Und francitas ist die Steuerfreiheit oder das steuerfreie Besitzthum ${ }^{3}$ ). Solcher Freiheit erfreute sich namentlich der Adel der Franken, die leodes ${ }^{4}$ ), die in erster Linie zu den franci gehören, aber auch die vornehmeren Classen anderer Stämme des fränkischen Reichs: so die sächsischen Adeligen in der karolingischen Zeit, während später die Schöffenbarfreien oder die Erfexen die Steuerfreiheit geniessen ${ }^{5}$ ), die baierischen nobiles ${ }^{6}$ ), dann im Süden die Gothen ${ }^{7}$ ). Die Romanen aber wurden franci durch einen Rechtsact, in dem sich Bestandtheile der germanischen Schwertleite mit dem Schlage verbanden, der im römischen Rechte der fränkischen Zeit die Form der vollsten Freilassung war, also durch das, was später als Ritterschlag erscheint ${ }^{8}$ ). In der That tritt ja auch im Laufe der Zeit der schwere Reiter, der miles, bezüglich der Steuerfreiheit an Stelle des homo francus. Die Steuerfreiheit des ältesten Adels geht über auf die Ritterschaft ${ }^{9}$ ). Auch die Kirche,

1) I S. 37 f. - ${ }^{2}$ ) I S. 34, 35, 38, 409, vgl. aber 74. Man muss einen weitern und einen engern Sinn von francus unterscheiden I S. 38. Frank oder frei im weitern Sinn heisst vielfach bis über das Mittelalter hinaus jeder, der eben nur von privater Herrschaft frei ist, auch wemn er eine öffentliche Abgabe zahlen muss. Im engern Sinne dagegen bedeutet frank oder frei den von jedem, auch dem öffentlichen Zins Befreiten. Gerade so hat exercitalis eine weitere und eine engere Bedeutung I S. $48 \mathrm{ff}$. Nach jener ist exercitalis der Freie, der liber, überhaupt, also auch der steuerpflichtige, nach dieser der steuerfreie nobilis. - ${ }^{3}$ ) I S. 35 vgl. I S. 3. Ueber die agri mutabiles I· S. 36. - 4) I S. 35, 381, 406, 423, II S. 160, $174 \mathrm{f}$. Im französischen Süden begegnen diese steuerfreien Vornehmen auch als Salici. I S. 479. Vgl. dazu I S. 4: Der Unterthaneneid heisst leodesamio, weil, wie später sich zeigen wird, nach Mayer die Kriegspflicht von den Leudes auf alle Unterthanen überhaupt erstreckt wurde. Man beachte, dass so, allerdings in neuer Form, die von Paul Roth zu Grabe getragene Leudestheorie bei Mayer ihre Wiederauferstehung feiert. Näheres darüber unten in Abschnitt IV. - ${ }^{5}$ ) I S. 39 mit N. 109 (Vgl. dazu Wilhelm Gundlach, Karl der Grosse im Sachsenspiegel, Gierkes Untersuchungen Heft 60, Breslau 1899 S. 19 ff., 32). - ${ }^{6}$ ) I S. 409. - ') I S. 34,

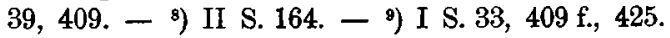


die ursprünglich überhaupt keine Steuerfreiheit besass, hat in mühseligem Kampfe das frühe Mittelalter hindurch allmählich das Recht der homines franci errungen ${ }^{1}$ ). So schliesst die Entwickelung damit ab, dass milites und clerici als die privilegirten Stände erscheinen.

Die Ausdehnung der Steuerfreiheit nach der Reichsgründung brachte also eine gewisse, wohl nicht unerhebliche Vermehrung des Adels mit sich. Sonst wirkte alles zusammen, um diesen Stand zu verringern. Schon in germanischer Zeit erlitt er starke Verluste durch Abfluss nach oben wie nach unten. Nach oben, indem aus den adeligen Geschlechtern, die so zu mediocres wurden ${ }^{2}$ ), diejenigen Sippen ausschieden, welche allmählich von gewählten Häuptlingen zu erblichen Fürsten (primi), später auch freien Herren sich erhoben ${ }^{3}$ ). Nach unten, indem diejenigen Angehörigen der Adelsgeschlechter, welche bei der Radicirung der Markberechtigungen kein Handgemal erhielten, in den Stand der gemeinen Freien hinabsanken ${ }^{4}$ ). Dazu trug der ältere Adel wie jeder Geburtsstand den Todeskeim in sich. „Denn social gilt zu allen Zeiten unter den Reichen das Princip der Ebenburt; in den deutschen Gebieten aber scheint sich dasselbe sehr früh zu einem Rechtsgrundsatz verdichtet zu haben, der unter Umständen durch hohe Strafen arbeitet." ${ }^{5}$ ) „Die Höfe und damit die Berechtigungen selber ballen sich dann naturgemäfs in der Hand weniger berechtigter Familien zusammen $\left.{ }^{6}\right)$, die einem langsamen Aussterben verfallen. Und endlich führte eine allgemeine Malsregel der ersten Karolinger dazu, dass der Geburtsadel recht eigentlich seines Stammes beraubt wurde. Es wird im nächsten Abschnitt davon die Rede sein, wie nach Mayer im Zusammenhang mit der sog. Säcularisation des fränkischen Kirchengutes die Grosszahl der homines franci unter die Panzerreiter ging und damit in die neue Nobilität übertrat. Nur geringe Bruchtheile des Standes machten diesen Schritt nicht mit und erschienen so auch weiterhin als Vertreter eines Adels, der nicht ritterlich war. Dahin gehören vor Allem die Schöffenbarfreien des sächsischen Rechtes ${ }^{7}$ ). Bei ihnen

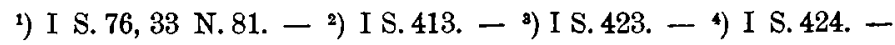
в) S. $422,479 . \quad-{ }^{\circ}$ ) ebenda. - 7) I S. $399 \mathrm{ff}, 407,479,425 \mathrm{f}$. Vgl. I S. 40. 
gilt Erstgeburtsrecht ${ }^{1}$ ), und sie sind Erfexen ${ }^{2}$ ); also gehen sie auf die Vornehmen der Hundertschaft zurück ${ }^{3}$ ). Aus ihnen wurden einst die ständigen Schöffen für das Grafschaftsgericht ernannt, bis das Schöffenamt zum erblichen Besitzthum des Geschlechtes sich herausbildete ${ }^{4}$ ). Wenn zur Zeit des Sachsenspiegels diese Sippen bereits so zurückgegangen sind, dass man sich genöthigt sah, ausser dem Aeltesten des Geschlechts, der allein den Schöffenstuhl ererbt hat, auch andere Geschlechtsgenossen zum Urtheilfinden zuzulassen, ja sogar immer häufiger von diesen altberechtigten Familien abzugehen ${ }^{5}$ ) und Ritterliche, selbst solche aus der Dienstmannschaft, zuzuziehen ${ }^{6}$ ), so sind das eben die letzten Züge eines im Todeskampf liegenden uralten Geburtsstandes ${ }^{7}$ ). Endlich liegt auch die Zugehörigkeit zu den homines franci der fränkischen Zeit offen zu Tage. Das Schöffengut ist ein Handgemal, also ein steuerfreies Gut $^{8}$ ), und wie die andern homines franci haben sich die Schöffenbarfreien das Wergeld von 600 solidi oder 100 solidi merowingischer Währung bewahrt ${ }^{9}$ ). Dazu kommt die Minimalausstattung von drei Hufen für die, die neu zu Reichsschöffen gemacht werden ${ }^{10}$ ): es sind also die Schöffenfamilien diejenigen, welche nach karolingischem Recht den Reiterdienst, aber nicht den Panzerreiterdienst zu leisten hatten ${ }^{11}$ ). Das führt uns auf den öffentlichen und den privaten Kriegsdienst, auf den Dienstadel und das Lehenswesen.

IV.

Die öffentliche Dienstpflicht besteht, seit es überhaupt ein Königthum giebt, diesem gegenüber; der Heerbann ist ein Urrecht des Königs ${ }^{12}$ ). Dabei blieb es auch in Deutschland, wo freilich das allgemeine Aufgebot verhältnissmässig früh verschwand, weil für den meist ausserhalb des Landes, in Italien, kämpfenden König der volksrechtliche Auszug, der Kriegsdienst aller, die nicht als schwere Panzer-

1) I S. 400. - ${ }^{2}$ ) oben S. 136. -- ${ }^{3}$ ) I S. 39. - 4) I S. 399, 403, 401. 8) Wogegen Eike sich sträubt und am alten Recht festhält. I S. 401. 6) I S. 400 f. - ${ }^{7}$ ) Vgl. z. B. I S. 395 f., 422. - ') I S. 47, 399, 415. 9) I S. 400. Siehe die von der bisherigen abweichende Berechnung aus Ssp. III $45 \$ 1$ bei Mayer I S. 428 N. $74 .-{ }^{10}$ ) I S. $400 .-{ }^{11}$ ) I S.400, 406. _-12) I S. 150 f., 189 ff., II S. 398. 
reiter dienten, keinen Werth besass. Dagegen brachten in Frankreich, wo die localen Kriege die Regel waren, die Grafen den Heerbann an $\operatorname{sich}^{1}$ ).

Pflichtig sind zunächst die Freien mit ihrer Person ${ }^{2}$ ). Doch beginnt schon früh die Umlegung auf die Güter ${ }^{3}$ ). Und nun werden auch Hörige (Liten) und Unfreie herangezogen, sofern sie selbständig sind, d.h. ein eigenes Anwesen, einen Hof für sich haben ${ }^{4}$ ). Freilich beschränkt sich die Pflicht der letztern wohl überall auf die Landwehr ${ }^{5}$ ); sie brauchen bloss im bestimmten Umkreis oder eine oder zwei Tagereisen weit bei der Vertheidigung mitzuthun. Nur die herrschenden Germanen haben dem Aufgebot über die Grenze zu folgen, nur sie sind auszugpflichtig ${ }^{6}$ ).

Der Pflichtige thut seinen Dienst entweder zu Fuss oder als leicht Berittener oder als schwerer Panzerreiter; jede dieser Dienstarten erschien als Erfüllung der öffentlichen Heerpflicht ${ }^{7}$ ). Die armen Leute leisten regelmälsig den Dienst zu Fuss (hostis, exercitus), werden aber gewöhnlich auch nur zur Landwehr verwendet wie die Unfreien ${ }^{8}$ ). Ausnahmsweise treten sie, wie es die karolingische Gesetzgebung vorsah, zu Verbänden zusammen und stellen dann wohl einen Reiter ${ }^{9}$ ). Ebenso dienen alle Vermöglicheren, alle, welche

1) I S. 125, 126, 133. - 2) I S. 119. Darum erscheint in den Polyptychen des 9. Jahrhunderts nach der Radicirung das hostilitium als Last des mansus ingenuilis. Es bildet eine Ausnahme, wenn das Polyptychum Irminos mit einem hostilitium vom gleichen Betrag auch den mansus lidilis belastet, I S. 119 mit N. 31, S. 123, 60. Das hostilitium war übrigens nicht nur Ablösung der allgemeinen Wehrpflicht, sondern namentlich auch Transport- und Verpflegungslast, welche neben dem Kriegsdienst bestand. I S. 61 ff. Vgl. dazu die interessanten Bemerkungen von R. Kötzschke, Zur Geschichte der Heeressteuern in karolingischer Zeit, Histor. Vierteljahrsschr. herausg. v. G. Seeliger II 1899 S. $231 \mathrm{ff.} \mathrm{-}{ }^{3}$ ) I S. 113, 123. Wer mehrere belastete Höfe besitzt, muss also für mehrfache Leistung sorgen. I S. 135. - *) I S. 120, 122. Im fränkischen Hauptland bestand wie in den bairischen und gothischen Nebenlanden ursprünglich nur eine Auszugpflicht der Franken bezw. Baiern und Gothen (hispani), während zwischen Seine und Loire von jeher auch die Römer pflichtig waren. I S.123. - ${ }^{5}$ ) I \$. 117, wovon die Wachtpflicht in den Städten ein Anwendungsfall ist. I S.118. ') I S. 122. - ${ }^{7}$ ) I S. $110 \mathrm{ff} ., 135$. - $^{8}$ ) I S.113, 116. - ') ebenda, dazu I S. $34,113 \mathrm{f} ., 115$. 
nicht durch einen Verband gestellt sind, und mindestens 3-4 Mansen haben ${ }^{1}$ ), als caballarii. Die cavalcatio war "mehr Beförderungsform als Kampfform"; man zog dabei zu Pferd aus und stritt zu Fuss ${ }^{2}$ ). Die caballarii bildeten in fränkischer Zeit den Gegensatz zu den Panzerreitern ${ }^{3}$ ). Als solche dienten diejenigen, welche 10-12 Mansen und mehr hatten ${ }^{4}$ ). Der schwere Reiterdienst erforderte eben für jeden, der ihn that, 3 Pferde und 2 scutarii $^{5}$ ); darum musste, wer $\mathrm{zu}$ ihm verpflichtet werden sollte, wenigstens das Dreifache vom Mindestmals dessen besitzen, der als leichter Reiter mit 1 Pferd zu dienen hatte.

Aller dieser öffentliche Heerdienst aber, in welcher Gestalt er auch geleistetwurde, hatte seine zeitlichen Schranken ${ }^{6}$ ). Aus den beschränkten Verhältnissen der germanischen Kleinstaaten wurde in das fränkische Grossreich der Grundsatz herübergenommen, dass der Pflichtige vor dem Feinde nur 6 Wochen (40 Tage) zu dienen habe, wozu dann noch 6 Wochen für den $\mathrm{Zug}$ an die Grenze (expeditio) und 6 Wochen für die Heimfahrt (Schachtruhe ${ }^{7}$ )) kamen, sodass alles zusammen das Vierteljahr ausmachte, wofür der Pflichtige nach den Capitularien sich zu verproviantiren hatte, oder genauer 3 germanische Mondmonate ${ }^{8}$ ).

Diese Beschränktheit der öffentlichen Dienstpflicht und daneben in gewissem Sinne auch das Bedürfniss nach Vermehrung der Panzerreiterei gab Anlass zur Entstehung des Lehenswesens ${ }^{9}$ ), das also keineswegs das Mittel war, durch welches das Reiterheer erst geschaffen wurde ${ }^{10}$ ).

1) I S. 113, 114, 116, 128. - ${ }^{2}$ ) I S. 112. - ${ }^{3}$ ) Alle Reiter sind caballarii, im weitern Sinn auch die Panzerreiter; aber nicht jeder caballarius ist schwerberitten. Vielmehr erscheinen als caballarii im engern Sinn gerade die geringern, die leichten Reiter I S. 114, 129. Ebenso ist der Panzerreiter ein miles, aber nicht alle milites sind Panzerreiter I S. 131. - ${ }^{4}$ ) I S. 132, 133, 135. - ') I S. 128. ') I S. 118 f., 129 ff., 135. - 7) D. h. der Moment, in dem das ganze Contingent die Heimkehr beginnt, und die Waffen in die Heerwagen ge-

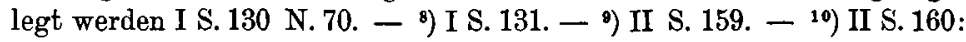
„Der Grund zu dem allen(Begünstigung der Commendation und Verleihung von beneficia aus säcularisirtem Kirchengut) kann nur gewesen sein, dass man an Stelle der zeitlich beschränkten Wehrpflicht der milites eine unbeschränkte Wehrpflicht setzen wollte. Das ist allerdings 
Neben der öffentlichen Dienstpflicht ging nämlich einher die private ${ }^{1}$ ). Sie beruhte entweder auf Gefolgschaft oder auf Unfreiheit ${ }^{2}$. In beiden Fällen war die Dienstpflicht, wenigstens ursprünglich und noch in karolingischer Zeit, unbeschränkt ${ }^{3}$ ). Beide Dienstformen eigneten sich also vortrefflich dazu, Kriegsvolk zu längerem Krieg zu verschaffen. Doch konnte für die Erstreckung der öffentlichen Dienstpficht über das volksrechtliche Mafs hinaus nur die Gefolgschaft in Betracht kommen. Von ihr sei jetzt zunächst die Rede.

Wem ein Herr Ross und Waffen reicht, der muss ihm dafür und damit dienen, bis er stirbt, worauf das Empfangene zurückzugeben ist (Mannfall), oder bis er durch den Tod des Herrn (Herrenfall ${ }^{4}$ )) oder sonst nothwendigen oder statthaften Anlass zur Rückgabe erhält ${ }^{5}$ ). Desgleichen trifft diese Dienstpflicht den, welchen ein Herr zu diesem Zwecke mit Land begabt ${ }^{6}$ ). Ein Gefolgschaftsverhältniss ist

richtig, dass im 8. Jahrhundert die Könige die schwere Rüstung der Reicheren durchzusetzen suchen. Aber wenigstens, soweit man sehen kann, wird das nicht direct dadurch erreicht, dass man die Bildung von Gefolgschaften begünstigt, wie umgekehrt vielleicht auch nicht jeder Gefolgsmann (vassus) ein Panzerreiter gewesen sein mag, sondern man knüpft an den Besitz von 10(12) mansus die öffentlichrechtliche und darum zeitlich begrenzte Verpflichtung, gepanzert auszuziehen. Das treibende Moment, das den König die Commendation an Grafen und königliche Vassallen begünstigen liess, liegt - ich wiederhole es - darin, dass man die zeitlichen Schranken der Heerpflicht wegräumen wollte. In Deutschland ist das für den Römerzug wirklich gelungen."

1) I S. 135: ${ }_{n} \mathrm{Je}$ mehr freilich die grösseren Besitzer sich commendiren, um so mehr verliert sich der Gegensatz von öffentlichem und privatem Heerdienst". - 2) I S. 425: "Die Panzerreiter, welche gewöhnlich der Vassallität oder Ministerialität angehören". II S. $121 \mathrm{ff}$., 184 ff. - ${ }^{3}$ ) II S. 156 ff., I S. 135. Wenn später, namentlich im 13. Jahrhundert, z. Th. auch der Mannendienst sich auf 40 Tage beschränkt, so hat dabei die öffentliche Heerpflicht die private beeinflusst, die eben thatsächlich meistens im öffentlichen Krieg zur Bethätigung gelangte. *) Darnach würde sich Mayer II S. 162 also, u. z. mit neuer Begründung, den von mir, Lehen und Pfründe in dieser Zeitschrift XX 1899 S. 244 aufgeführten Schriftstellern anreihen, die den Herrenfall beim Lehen auf das Dienstverhältniss oder genauer auf die Vassallität zurückführen. Siehe aber unten A. 76. - s) II S. $161 \mathrm{f}$. - 6) II S. 171: „Das beneficium ist eine Schenkung für Kriegsdienst, und deshalb kann es zurückgefordert werden, wenn das Dienstverhältniss beendet ist, aller- 
damit nicht nothwendig und nicht immer begründet. Es scheint, dass die karolingischen Hausmeier und Könige viele leodes und sonstige Adelige mit Panzer und Land ausgestattet haben, ohne dass diese darum ins königliche Gefolge eintraten ${ }^{1}$ ). Aber allerdings, wo ein Gefolgschafts-

dings ursprünglich nicht mit dinglicher, sondern (wegen des Uebergangs der Gewere auf den Sohn) mit persönlicher Klage". II S. 172: "Vor allem aber wirkt das Herrenrecht, wenn das Dienstverhältniss durch den Tod des Herrn oder Vassallen aufgelöst wird. Hier kann der Herr die Rückgabe verlangen, wenn nicht von Seiten des Mannes das Verhältniss neu geknüpft wird“.

1) II S. 160: „Es wird sich zeigen, dass der König wahrscheinlich Waffen, vielleicht aber auch Benefizien an die franci (leodes) überhaupt gegeben hat, nicht bloss an sein Gefolge, und man kann dann weiter vermuthen - aber ohne Beleg - dass diese Schenkungen dazu verwendet worden sind, um den Besitz vieler franci über das landrechtliche Minimum für den Panzerreiterdienst zu bringen und ihn mit schwerer Rüstung auszustatten. Aber selbst wenn diese Vermuthung richtig sein sollte, so wäre das juristische Vehikel für die Vermehrung der Panzerreiter nicht die Gefolgschaft, sondern die Wehrpflicht des öffentlichen Rechts und vielleicht die Waffenreichung." Und sodam II S. 166 f.: „Im Süden ist die francitas, von der der Ritterdienst und juramentum fidelitatis zu leisten ist, kein Lehen, sondern Allod. In Sachsen haben sodann die Schöffenbarfreien einen Heerschild, wiewohl sie anscheinend keine Mannen zu sein brauchen. Der Heerschild - die Bezeichnung für den ritterlichen Dienst - aber wird als Königsschild bezeichnet; das weist doch darauf, dass er vom König stammt ..... All das zusammen (mit Helmolds Nachricht über die Werbungen des Etheler) legt den Gedanken nahe, dass zwar die Gefolgsherren an ihre Leute Waffen reichen, dass aber der König oder für ihn der Graf nicht nur an die Gefolgsleute die Waffen giebt, sondern an die homines franci überhaupt, die zu persönlichem Treueid an den König (oben S. 134 A.4) und deshalb von jeher zu Kriegsdienst verpflichtet waren ..... In der Zeit, in der dann die Panzerrüstung eingeführt wurde, hätte der König Panzer vertheilt, soweit das nicht durch die Gefolgsherren geschah.“ Bezüglich der Benefizialleihe aber siehe II S. 174 f.: „Es wäre recht wohl denkbar, dass, wie wahrscheinlich die Waffenreichung auch an andere als Gefolgsleute geschehen ist, so Schenkungen vom König oder den Grafen an andere als Gefolgsleute gemacht wurden. Man kann damit die Nachrichten der Merowingerzeit zusammenbringen von Königsschenkungen, die sich nicht auf den Kreis der königlichen Antrustionen beschränken, und von den Leudes, welche deutlich den Bauern der Dorfmarken gegenüberstehen, und die so eine vornehmere Classe bilden, in näherer Verbindung zum König . . . . All das macht es möglich - feste Behauptungen wage ich nicht - dass neben der 
verhältniss eingegangen wird, da kommt es von Seite des Herm zu der unvererblichen ${ }^{1}$ ) Gabe oder, bezw. und zur Verleihung eines auf die Nachkommen vererblichen ${ }^{2}$ ) Lehens ${ }^{3}$ ), zu jener, wenn der Gefolgsmann im Hause des Herrn wohnt, zu dieser oder vielmehr zu beidem, wenn er nicht mehr casatus ist, wenn er selbständig wirthschaftet ${ }^{4}$ ). Der Mann leistet dafür neben dem Treueid die Mannschaft; er geht dem Herrn in die Hände ${ }^{5}$ ). Doch kam es ursprünglich zu solcher Handreichung nur beim ausschliesslichen Dienstverhältniss, also dann, wenn der Mann (homo oder baro) lediglich diesem Herrn angehören wollte ${ }^{6}$ ). Von dieser ausschliesslichen Zugehörigkeit eines Mannes zu einem Herrn ist überhaupt die Entwickelung ausgegangen. Der Mann lebte ja damals auch noch im Hause des Herrn ${ }^{7}$ ). Erst später, nach Abschichtung der Gefolgschaft, wurde die Commendation auch bei mehrfacher Lehensverbindung verwendbar ${ }^{8}$ ), wo man sich sonst nur mit mehreren iuramenta fidelitatis $\mathrm{zu}$ helfen vermochte ${ }^{9}$ ).

Gefolgschaft noch ein weiterer Kreis Abhängiger stand, zusammengehalten durch Schenkungen an die leodes oder franci."

1) Daher das casalagum oder casamentum, die prekäre Gabe auch von Land im Gegensatz zum feodum II S. 20 f., 174. - ${ }^{2}$ ) Das Lehen ist nach deutschem wie nach französischem Recht von jeher vererblich auf die Nachkommenschaft, weshalb auch der Satz gilt: der Todte erbt den Lebendigen (oben S. 141 A.6), und die Klage des Herrn beim Mannfall nur als persönliche gedacht werden kann. II S. 168 und 174. Beim unvererblichen Lehen spielt die Gabe hinein. ${ }_{n}$ Nicht auf eine Entwickelung von der Unvererblichkeit zur Vererblichkeit geht die Geschichte des Lehensrechts hinaus, sondern auf ein Nebeneinander beider Formen, bis die Unvererblichkeit wegfällt." - ${ }^{3}$ ) II $\mathrm{S} .167 \mathrm{ff}$. Die eigentliche deutsche Bezeichnung dafür liege dem mittelalterlichlateinischen honor zu Grunde (vgl. verehren), das also nicht in erster Linie das Amt und dann erst das Amtslehen bedeute; beneficium und feodum seien die westfränkischen Bezeichnungen. Beim Lehen bezieht der Mann das ganze Einkommen. Dadurch unterscheide er sich von demjenigen Beamten, der nur einen Antheil an den abzuliefermden Gefällen zugewiesen erhält, und vom Soldempfänger oder Besoldeten, dessen Gehalt an die Prebenden der Hofverwaltung anknüpfe. Vgl. II S. 120 mit 168. - 4) II S. 167. Man beachte, dass Ma y er hier casatus gerade im entgegengesetzten Sinn verwendet, als das sonst geschieht. $\left.{ }^{5}\right)$ II S. $144 . \quad{ }^{8}$ ) II S. $145 . \quad{ }^{7}$ ) II S. 146, 141. - ${ }^{8}$ ) S. 144, 145. 9) II S. 145 . 
Ein Gefolge konnte zunächst nur der König haben ${ }^{1}$ ). Auf die ausschliessliche königliche Gefolgschaft geht der Fürstenstand und die Baronie zurück. Die altfränkische Bezeichnung für die dem König allein zugehörigen Gefolgsleute war antrustiones ${ }^{2}$ ). Die Antrustionen kennzeichnet das jedenfalls in der Hausgemeinschaft mit dem Herrn ausgebildete $^{3}$ ) Zustimmungsrecht zu dessen Handlungen ${ }^{4}$ ), die persönliche Gerichtsbarkeit des Herrn über sie, die, weil hier Herr und König zusammenfallen, sogar die Hochgerichtsbarkeit in sich schliesst ${ }^{5}$ ), und endlich der Titel optimates ${ }^{6}$ ). All dies kommt auch den königlichen Vassallen zu. Also sind die Vassallen des Königs nicht eine jüngere Schicht der Gefolgschaft, sondern nur dem Namen nach von den Antrustionen verschieden 7). Freilich mischten sich fremde Elemente ein. Aus dem römischen Recht stammt wie die Bezeichnung als viri illustres so die Stellvertretungsbefugniss, welche nach französischem Recht ausnahmsweise den Baronen für das ordentliche Gericht zukommt ${ }^{8}$ ). Keltisch aber ist der Name vassus ${ }^{9}$ ), die Erblichkeit des Vassallenverhältnisses auf Seiten des Mannes im südfranzösischen Recht ${ }^{10}$ ), wohl auch der Anfall des ganzen Fahrhabevermögens an den Herrn selbst bei ganz geringem Dienstvergehen des Mannes ${ }^{11}$ ) und endlich die fast bis zur völligen Gleichstellung gehende Annäherung der freien Gefolgschaft an die unfreie Dienstmannschaft, die in mittel - und südfranzösischen Urkunden zu Tage tritt ${ }^{12}$ ). Aber hiervon abgesehen stimmt die königliche Vassallität der karolingischen Zeit mit dem altfränkischen Antrustionat gerade so überein wie mit dem nachkarolingischen Fürsten- oder Baronenthum. Fürsten oder principes oder königliche Barone sind nämlich nachmals in Deutschland wie in Frankreich diejenigen königlichen Vassallen, die von jeher nur dem König Mannschaft

1) II S. 153, 176. - ${ }^{2}$ ) II S. $147 \mathrm{f} . \quad{ }^{\text {s) }}$ Aber später vom Aufenthalt am Hof unabhängige Il S. $\left.60 .-{ }^{4}\right)$ II S. $135 \mathrm{ff} ., 145,59 .-$ 5) II S. 136 ff., 141 f., 148. - ') II S. 131 f., 148. - 7) II S. 148. $\left.{ }^{8}\right)$ II S. $\left.149 \mathrm{ff.}, 82 .-{ }^{9}\right)$ II S. $149 .-{ }^{10}$ ) II S. $142 \mathrm{ff} ., 149 .-{ }^{11}$ ) II S. 143, 149. - ${ }^{12}$ ) II S. 143, 149, 188, 59 f. ${ }_{n}$ Es bleibt nur der rein militärische Unterschied zwischen dem schweren und dem leichten Reiter übrig." 
thaten und nur ihm zugehörten ${ }^{1}$ ), unter Umständen also auch solche, die noch hinter den Grafen stehen ${ }^{2}$ ), wie denn in der That nach einem für die Standesbezeichnungen allgemein geltenden Gesetz gerade diesen freien Herren, als der untersten Schicht der königlichen Gefolgschaft, der Name Barone schlechthin geblieben ist $^{3}$ ). In Frankreich trat übrigens schon früh eine Zersetzung der königlichen Gefolgschaft ein. Einmal gewinnen jetzt unter den pares, wie die ausschliesslich einem Herrn dienenden Gefolgsleute auch heissen ${ }^{4}$ ), die zwölf die erste Stelle, welche im Königsgericht das Urtheil finden und überhaupt bei Hofe die Entscheidung geben ${ }^{5}$ ); das ist der Ursprung der vielumstrittenen pairs de France ${ }^{6}$ ). Und sodann begeben sich dort schon im 12. Jahrhundert die königlichen Barone in Abhängigkeit auch von andern Baronen ${ }^{7}$ ). In Deutschland dagegen bewirkte noch um dieselbe Zeit die Thatsache, dass ein Theil der königlichen Gefolgschaft auch zu andern Herren in Lehensverbindung trat, eine wichtige Einschränkung im Bestand der Reichsfürsten, nämlich das Ausscheiden aller Freiherren oder Barone im engern Sinne, wie auch der meisten Grafen ${ }^{8}$ ). Erst zu Anfang des 13. Jahrhunderts schloss sich der ursprünglich nach dem Princip der Ausschliesslichkeit gebildete Fürstenstand so vollkommen ab ${ }^{9}$ ), dass nunmehr dieses Princip aufgegeben werden konnte und die Reichsfürsten, auch wenn sie Vassallen eines andern königlichen Vassallen wurden, ihren Stand nicht mehr verloren, wie auch der zum Reichsfürsten Erhobene nicht aus seinen bisherigen Lehnsverbindungen ausschied ${ }^{10}$ ).

2) II S. 129, 131, 135. Im Westen entspricht dem der Begriff des ligius II S. 133. Vgl. übrigens bezüglich der Normandie II S. $121 \mathrm{ff}$,, 125; bezüglich Franciens S. 125 ff. - 2) II S. 131, 133, $146 \mathrm{f.}-{ }^{3}$ ) II S. 133, 147: „Die freien Herren werden in Deutschland wohl deshalb Barone genannt, weil sie die geringsten Barone des Königs sind." 4) I S. 389. - $^{5}$ ) ebenda. - ${ }^{6}$ ) I S. 390 mit N. $\left.22,407 . ~-~ 7\right)$ II S. 146, 127. Die geringern Ritter, die jetzt durch irgendwelchen Zufall directe Vassallen des Königs werden, erhalten nun nicht mehr die Stellung von Baronen, auch nicht bei Ligietät. ${ }^{-8}$ ) II S. 146, 147. - ${ }^{9}$ ) Ueber seine geistlichen Mitglieder siehe II S. $151 \mathrm{ff}$. uud dazu meine Abhandlung, Lehen und Pfründe in dieser Zeitschrift XX 1899 S. 234 mit A. 2. 10) II S. $129 \mathrm{f}$., $145 \mathrm{f}$.

Zeitschrift für Rechtsgeschichte. XXI. Germ. Abth. 
Die königlichen Gefolgsleute erhalten nun aber auch selbst das Recht, Vassallen zu haben ${ }^{1}$ ). Als Karl Martell und seine Söhne Panzerreiter mit unbeschränkter Dienstpflicht sich zu verschaffen trachteten, „konnte dabei natürlich nicht die Form gewählt werden, dass man die milites direct in das königliche Gefolge aufgenommen hätte. Denn dieses, welches noch in der französischen Zeit nur etwa 100 Leute befasst, ist $\mathrm{zu}$ vornehm und abgeschlossen für neue Genossen (pares), die in grösserer Zahl und deshalb in geringerer socialer Stellung eingetreten wären. Deshalb wird der Weg eingeschlagen, dass sich die Krieger den Grafen und den andern königlichen Vassallen commendiren. Da aber diese neuen Vassallen dann natürlich nicht mehr ihr bisheriges eigenes Anwesen verlassen und sich dem Haushalt ihrer Gefolgsherren anschliessen konnten, so wird es nothwendig, dass ihnen beneficia gegeben werden " ${ }^{2}$ ), zu welchem Zweck eben der König die Grossen mit säcularisirtem Kirchengut ausrüstet. Uebrigens erlangen in Deutschland wie in Frankreich wohl noch in karolingischer Zeit auch diese Vassallen der königlichen Barone die Befugniss zur Bildung von Gefolgschaften ${ }^{3}$ ), bis schliesslich alle Schranken der activen Lehensfähigkeit beseitigt wurden ${ }^{4}$ ).

Inzwischen war die Zeit der unfreien Reisigen gekommen; seit der fränkischen Zeit haben der König und die Grossen neben den freien Vassallen unfreie Vavassoren ${ }^{5}$ ). Sie dienen ursprünglich nur mit Schwert, Schild und Lanze als leichte Reiter ${ }^{6}$ ) und steigen erst im Laufe der Zeit zur schweren Reiterei auf, um mit den Vassallen zusammen die Ritterschaft zu bilden ${ }^{7}$ ). Aus seinen bezw. des Reichs ${ }^{8}$ ) unfreien Reisigen bestellt der König seinen Baronen den Hof; nur weil der König sie ihnen einräumt, haben die Fürsten eine vollständige Hofhaltung, und nur aus den Reichsdienstleuten dürfen sie ihre Hofdiener nehmen, weshalb auch der Name ministerialis oder Dienstmann den höchsten unfreien Hofbeamten des Königs und der Fürsten vorbehalten

1) II S. $153 \mathrm{ff} .-{ }^{2}$ ) II S. 159, 160. - ${ }^{3}$ ) II S. $153 \mathrm{ff}$, insbesondere 156; davon spreche das Recht der Champagne und der Sachsenspiegel. - 4) II S. 156. - ") II S. $184 \mathrm{ff} .-{ }^{6}$ ) II S. $185 \mathrm{ff.}, 188$. 7) II S. $\left.188,193,194 .-{ }^{8}\right)$ II S. $190 \mathrm{ff}$. 
bleibt ${ }^{1}$ ). Die Angleichang an den freien Ritter ${ }^{2}$ ) vollzieht sich dadurch, dass dem Dienstmann kein anderer Dienst mehr zugemuthet wird als Kriegs- und Amtsdienst ${ }^{3}$ ), ferner durch Einräumung eines Dienstgutes, auf das wenigstens einige von den Grundsätzen des Lehensrechtes bald Anwendung finden, insbesondere der, welcher die Annahme von Lehen auch Anderer als des ursprünglichen Herrn gestattet ${ }^{4}$ ), sodann mit dem Eintritt der Ministerialen ins Grafengericht ${ }^{5}$ ) und in den Send des Bischofs und endlich durch Zubilligung des Freienwergelds ${ }^{7}$ ). „Derjenige Ueberrest der alten Unfreiheit, der am längsten zu verspüren ist, besteht in der Befugniss des Herm, den Ministerialen, vielleicht nicht ohne Zustimmung seiner Genossen, aber ohne die eigene persönliche Zustimmung zu veräussern ${ }^{8}$ ). " Dabei bleibt als wichtiger Unterschied vom freien Ritter dauernd die Unvererblichkeit der gewöhnlich von unfreien Rittern bekleideten Aemter; nicht umsonst wird bald die villicatio, bald das Amt als das unvererbliche Recht dem feodum gegenübergestellt und erhält „Meierrecht" die Bedeutung "unvererbliches Besitzverhältniss" ${ }^{8}$ ). Im Uebrigen werden nunmehr auch Aemter der öffentlichen Verfassung mit Ministerialen besetzt, und umgekehrt übernehmen Freie ministerialische Aemter ${ }^{10}$ ). Man thut aber Unrecht, das Letztere als "ein Heruntersinken des freien Adels in die Ministerialität aufzufassen; umgekehrt, weil der Ministerialadel allmählich zum freien Adel aufgestiegen ist, übernimmt der Freie auch ministeriale Dienstverrichtungen" ${ }^{\text {111). }}$

V.

Ausser den Gefolgsleuten und den unfreien Dienern gehören zum Gesinde die Schutzgenossen; bei ihnen erscheint der Eintritt und die Theilnahme am herrschaftlichen Dienst nur als Mittel zum Zweck der Erlangung des durch den Herrn gewährten Friedens und Schutzes ${ }^{12}$ ). Solche

1) II S. 192. - ${ }^{2}$ ) Die ihren Abschluss findet mit dem Eintritt in den Heerschild. II S. 193. Vgl. über den Heerschild im Allgemeinen ebenda S. $153 \mathrm{ff} . \quad{ }^{\text {3) }}$ II S. 193. - ${ }^{4}$ ) ebenda. - ${ }^{5}$ ) II S. $194 \mathrm{f}$. $\left.{ }^{6}\right)$ II S. 195. - 7) II S. 198. - 8) II S. 199. - 9) ebenda. - 10) II S. 200. - 11) II S. 202. - $^{12}$ ) II S. 246. 
Schutzgenossen u. z. des Königs waren nach Mayer namentlich die Kaufleute und Bürger ${ }^{1}$ ).

Denn den einen Factor in der Geschichte der deutschen Stadtverfassung bildet nach ihm eine obrigkeitliche hansa. Ich fasse mich hier ganz kurz. Die Theorie ist ja schon aus Mayers älterer Untersuchung über Zoll, Kaufmannschaft und Markt zwischen Rhein und Loire ${ }^{2}$ ) bekannt. Doch hat sie Mayer in der Verfassungsgeschichte verbessert und ausgebaut, während er sie in einer seither erschienenen Abhandlung über Hansa und Hasbannus ${ }^{3}$ ) den Angriffen Rudolph Eberstadts ${ }^{4}$ ) gegenüber speciell für Paris und überhaupt für das nordfranzösische Recht aufrechterhält und mit weiterem Materiale zu stützen sucht.

Der reisende Kaufmann bedarf des Geleites ${ }^{5}$ ), d. h. wörtlich und ausnahmsweise einer ihn begleitenden Schutzmannschaft, in übertragenem Sinne aber und regelmälsig einer Rechtsstellung, die ihn gegen Angriffe ebenso sichert, als wäre er mit reisigen Leuten versehen, oder ihm doch im Falle der Verletzung die Bestrafung der Uebelthäter und Schadloshaltung gewährleistet ${ }^{6}$ ). $\mathrm{Zu}$ diesem Ende entrichtet er bei der Anfahrt zum Markt und bei der Abfahrt ${ }^{7}$ ) bezw. bei der Durchfahrt ${ }^{8}$ ) an den Grafen oder sonstigen königlichen Beamten ${ }^{9}$ ) jeweilen den conductus von 4 Denaren ${ }^{10}$ ), wodurch er, wenn er sich nicht geradezu auf Lebenszeit dem Könige commendirt ${ }^{11}$ ), zeitweilig als königlicher Munt-

1) Die Münzer nehmen nach Mayer II S. $280 \mathrm{ff}$. eine besondere Stellung ein. Es waren die Hausgenossen, die höher gestellte familia, die länger als die übrigen prebendarii Hofgenossen blieben, und deren Gewerbebefugniss niemals so individuell erblich geworden sei wie die anderer herrschaftlicher Handwerker. $-{ }^{2}$ ) Bis in das 13. Jahrhundert (Abhandlungen zum 70. Geburtstage von K. Maurer), Leipzig 1893 S. 377 ff. - ${ }^{3}$ ) oben S. 115 A. 1 und Oppermann im Correspondenzblatt der Westdeutsch. Ztschr. XIX $1900 \mathrm{Sp} .178 \mathrm{ff}$. - ') Das französische Gewerberecht und die Schaffung staatlicher Gesetzgebung und Verwaltung in Frankreich vom 13. Jahrhundert bis 1581, Leipzig 1899 S. 77 ; vgl. desselben Ursprung des Zunftwesens und die älteren Handwerkerverbände des Mittelalters, Leipzig 1900 S. 188. - ${ }^{\text {5) }}$ II S. $203 \mathrm{ff.}$ $\left.{ }^{\circ}\right)$ II S. 211, 212, $214 \mathrm{ff} . \quad{ }^{7}$ ) II S. 205, 208. - ${ }^{8}$ ) II S. 211, 212. - 9) II S. 209, $213 \mathrm{f} .-{ }^{10}$ ) Ueber dessen Verhältniss zu andern Abgaben II S. $212 \mathrm{f}$. - ${ }^{11}$ ) II S. 247, 248. Nicht als rechtsunfähige Fremde, sondern als 
mann in die königliche Hanse ${ }^{1}$ ) $\operatorname{tritt}^{2}$ ). Dies ist der eine Fall der Ergebung in die Hanse des Königs, der durch Specialgeschäft ${ }^{3}$ ).

Man kann aber Mitglied dieser Hanse auch dadurch werden, dass man dauernd den Markt unter Königsschutz bezieht ${ }^{4}$ ). Im ständigen Markt, der, wenn er sich an eine altumwallte Niederlassung anlehnt oder erst neu umwallt wird, zugleich Burg ist ${ }^{5}$ ), treten die Grosskaufleute ${ }^{6}$ ), wie sie ehedem als reisende Leute für den Jahr- und den Wochenmarkt gethan haben ${ }^{7}$ ), ebenfalls in die obrigkeitliche Hansa, aber dauernd, um für immer im besonderen Schutze des Königs oder Fürsten ${ }^{8}$ ) zu bleiben ${ }^{9}$ ) und fortan Bürger, burgenses, zu sein ${ }^{10}$ ). Die sonstigen Besucher des Marktes geniessen zunächst nur den durch die allgemeine Verkündung des Marktfriedens ${ }^{11}$ ) gewirkten Schutz des königlichen Sechzigschillingsbanns ${ }^{12}$ ). Aber bald treten die Einwohner zumal der alten Römerstädte gleichfalls unter das Marktrecht ${ }^{13}$ ) und ebenso der Handwerker ${ }^{14}$ ), der, wie übrigens auch der Kaufmann ${ }^{15}$ ) von alters her zu einem grossen Theil

Kaufleute sind in das königliche Gesinde getreten die Juden II S. $286 \mathrm{ff}$,, die Kammerknechte hiessen, weil sie dem Kämmerer unterstanden und Vorräthe zu liefern hatten II S. 319.

1) II S. 206, 211. - ${ }^{2}$ ) II S. 209, 210, 224, 226, 235, 246, 248. Ueber deren Verhältniss zur Gilde äussert sich Mayer II S. 236 ff., 242 so: „Die Hanse ist ein obrigkeitlicher Verband, in den man durch Zahlung an die Obrigkeit eintritt, und die Gilde eine Corporation, deren Mitglied man durch Zahlung an die Corporation wird". Mitunter sei allerdings die ganze Grosskaufmannschaft in die Hanse getreten, und so die Hanse an die Gilde gekommen. - ${ }^{3}$ ) II S. 266. - 1) II S. 266,

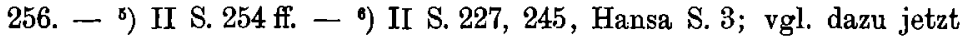
G. v. Below, Grosshändler und Kleinhändler im deutschen Mittelalter, Jahrbücher f. Nationalökonomie LXXV 1900 S. 1 ff., der nachweist, dass es im Mittelalter blosse Grosshändler so gut wie gar nicht gegeben hat. - 7) II S. 219 f., 221; Hansa S. 21. - ') II S. 217, 224, 258 ff., $263 \mathrm{ff}$. - 9) II S. 248, Hansa S. 13, weshalb sie nunmehr auch die 4 Denare jährlich oder zu jedem Jahrmarkt als ständige Abgabe zu entrichten haben II S. 211, $248 \mathrm{ff}$. - ${ }^{10}$ ) II S. $228 \mathrm{ff}$. - ${ }^{11}$ ) II S. $221 .-$ 12) II S. 224 f. - ${ }^{13}$ ) II S.254. - ${ }^{14}$ ) II S. 253; vgl. dazu Hansa S. 9 ff., 46. - ${ }^{15}$ ) II S. $180 \mathrm{ff}$. Der Bürger nähert sich überhaupt dem Ministerialen an. Darauf sollte nach Mayer II S. $230 \mathrm{ff}$. es deuten, wenn constabularii, ursprünglich die unter dem comes stabuli bezw. Marsehall stehenden leichten Reiter, die namentlich auch als Vollstreckungs- 
unfrei ist ${ }^{1}$ ), aber jetzt die Marktabgabe leicht aufbringt. Hier vollzieht sich also der Eintritt in die Hanse nach allgemeinen Grundsätzen; der Weg geht in diesem Falle durch das Marktrecht.

Die Zugehörigkeit zur Hanse bringt für den Einzelnen Zollfreiheit mit sich ${ }^{2}$ ), ferner das Reclamationsrecht ${ }^{3}$ ) und in Deutschland sowie in Nordfrankreich das dreifache Wergeld des Gemeinfreien ${ }^{4}$ ). Verfassungsgeschichtlich wichtiger sind die Folgen für die Gesammtheit. Das Markt- oder Bürgerrecht bedeutet nämlich nach Mayer negativ die vollständige Exemtion von der Gerichtsbarkeit des Landrechts ${ }^{5}$ ). Und positiv ergiebt sich aus ihm die besondere Nieder- ja sogar Hochgerichtsbarkeit ${ }^{6}$ ) und damit ein besonderes Straf-, Process- und Civilrecht ${ }^{7}$ ) der Bürger, das in seinen Grundzügen allenthalben dasselbe ist, weil ihm die für das ganze Reich einheitliche Hanse zu Grunde liegt ${ }^{8}$ ), und die Behörden aller Markt- und Burgorte Behörden ein und desselben Rechtes, Behörden für das königliche Gesinde sind ${ }^{9}$ ). Endlich hängt damit auch der Haubann zusammen, der nach Mayer als hansabannus zu verstehen ist, und als das die einheimische Kaufmannschaft nicht treffende Verbot an alle, die nicht Hansamitglieder sind, also namentlich an die Landleute aufgefasst werden muss, in der Stadt und innerhalb der Bannmeile zu verkaufen ${ }^{10}$ ).

Ein zweiter malsgebender Factor in der Stadtverfassungsgeschichte war nach Mayer der Friedensverband der Eidgenossenschaft ${ }^{11}$ ). Diese bringt nämlich die aus dem Marktrecht bezw. königlichen Gesinderecht stammende Hochgerichtsbarkeit an sich. „Durch sie wird die (strenge) herr-

beamte verwendet wurden, später die Bezeichnung für die jungen vornehmen Bürger werde, die eben auch leichtbewaffnet seien.

1) II S. $177 \mathrm{ff}$, 246. Below habe die Existenz unfreier Hand-

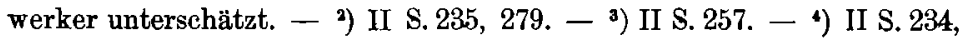
245. - b) II S. 257 . - b) II S. $221 \mathrm{ff.,} 266 \mathrm{ff.}$; vgl. 214, 216, Hansa S. 14. Die königliche Hofgerichtsbarkeit schliesst eben auch die Hochgerichtsbarkeit ein. - ${ }^{7}$ ) II S. $273 \mathrm{ff.}-{ }^{8}$ ) II S. 226 , Hansa S. 20 f. Die Hanse greift auch auf das platte Land hinaus; der obrigkeitliche Hansgraf der obrigkeitlichen Hanse steht auch den ländlichen hansati, den spätern Pfahlbürgern, vor. II S. 244 ff. - ') II S.274. - ${ }^{10}$ ) II S. 277 ff., Hansa S. $36 \mathrm{ff}$. - ${ }^{11}$ ) I $524 \mathrm{ff}$., besonders $538 \mathrm{ff}$. 
schaftliche Gerichtsbarkeit über Friedensbruch zu einer (milderen) Communalgerichtsbarkeit, oder besser die Communalgerichtsbarkeit, die von jeher geübt worden ist, erfasst jetzt auch die Stadt des Römer- und Marktrechts" "1). Das führende Organ dieser Eidgenossenschaft ist der Rath; der Unterstellung unter das deutsche Gemeinderecht verdankt er sein Aufkommen ${ }^{2}$ ).

Im Uebrigen freilich geht das communale Element auf ältere Wurzeln zurück, zu einem kleineren Theile auf germanische, indem das noch zu besprechende, nach Mayer germanische Schöffeninstitut in etwa in die Entwickelung hineinspielte ${ }^{3}$ ), wie auch der Einfluss germanischer Eidbruderschaften schon in älterer Zeit sich bemerkbar macht ${ }^{4}$ ), zum weit grössern Theile aber auf römische. Wir sind damit bei Mayers These von der Fortdauer und Nachwirkung der römischen Communalverfassung in fränkischer und nachfränkischer Zeit und beim dritten Factor der städtischen Verfassungsentwickelung angelangt. Das ist vielleicht derjenige Punkt, bei dem am ehesten Zweifel und Unglaube gegenüber Mayers Aufstellungen im Leser wach werden. Nicht sowohl deshalb, weil seine These gegen ein fast zum Dogma gewordenes Ergebniss der neueren, auf Hegels grundlegendem Werk über die italienische Städteverfassung fussenden Forschung verstösst ${ }^{5}$ ), sondern wegen Mayers eigener Beweisführung. Nirgends tritt seine Neigung zu kühnster - um nicht mehr zu sagen - Combination zu Tage als hier. Nirgends äussert sich mehr seine schwache Nachgiebigkeit gegenüber geistreichen, aber schlechterdings nicht zu rechtfertigenden Einfällen. Nirgends widersteht er weniger der Versuchung, irgend eine vereinzelte Erscheinung in einen ganz entlegenen, grossen Zusammenhang zu rücken unter souveräner Missachtung der Thatsachen und der von ihm allerdings als einseitig und trügerisch hingestellten Quellenlage ${ }^{6}$ ). Oder was sollen wir dazu sagen, wenn die

1) I S. $548,313$. - $^{2}$ ) II S. $550 \mathrm{ff} .-^{3}$ ) I S. $307 \mathrm{ff}$. - $^{4}$ ) I S. $526 \mathrm{ff}$. $\left.{ }^{-}{ }^{\overline{0}}\right)$ Mayer I $\mathrm{S} .284 \mathrm{ff} .-{ }^{8}$ ) Am ehesten kann man dem zustimmen, was Mayer I S. $320 \mathrm{ff}$. mit II S. 258 über die Ausbildung einer bischöflichen Stadtherrschaft zu eigenem Recht auf römischer Grundlage ausfübrt. Daran ist manches Richtige. 
Consuln ${ }^{1}$ ) der mittelalterlichen Städte, einfach deshalb weil sie gewöhnlich als Vierercolleg auftreten und das Amt jährlich wechseln, auf die quatuorviri bezw. doppelten duoviri iure dicundo und aediles der römischen Colonien und Municipien zurückgeführt werden ${ }^{2}$ ) - wenn die Dorfvierer insbesondere auch unserer oberrheinischen Dörfer ${ }^{3}$ ) als ländliche Nachbildung derselben römischen Städteinstitution ${ }^{4}$ ), und gar die mittelalterlichen Bürgermeister wegen ihrer Zweizahl (wenn es sein muss, auch der eine Bürgermeister und der Oberstzunftmeister) ${ }^{5}$ ) als die beiden Aedilen erklärt

1) Zur Erklärung der Bezeichnung I S. $311 \mathrm{f} .-^{2}$ ) I S. $285 \mathrm{ff}$, besonders S. 290 ff., 294, 297. Vgl. dazu Oppermann a.a. O. Sp. 182 . s) Vgl. namentlich Friedrich v. Wyss, Die schweizerischen Landgemeinden, Abhandlungen S. 46f. - ${ }^{4}$ ) I S.292, 304. Wean eine andere Herleitung als die z. B. von Wys angedeutete von den verschiedenen Theilen des Dorfs versucht werden sollte, so könnte man mit viel mehr Wahrscheinlichkeit die Viere als Vorsteher von Sippenvierteln sich vorstellen. - 5) Von Basel behauptet Mayer I S. 314, um die Zweizahl herzustellen, der Obristzunftmeister sei als einer der beiden Bürgermeister zu fassen. Nun wissen wir allerdings über die Errichtung beider Aemter nichts Näheres. Aber das steht fest, dass zunächst - etwa seit der Mitte des 13. Jahrhunderts, Urkundenbuch der Stadt Basel I 1890 Nr. 263 S. 191 (Text bei Trouillat, Monuments de l'histoire de l'ancien évêché de Bale I 1852 S. 592 Nr. 412), Nr: 283 S. 204 u. s. w., Heusler, Verfassungsgeschichte der Stadt Basel, 1860 S. 123 - nur einer der beiden Beamten, der Bürgermeister, da war. Noch in der auf Bischof Heinrich von Neuenburg zurückgehenden Handfeste wird nur er genannt, obschon für Erwähnung des Oberstzunftmeisters, der ja auch vom Bischof "gegeben“" wurde, aller Anlass war; Heusler, a. a. O. S. $127 \mathrm{ff}$., Basler Urkundenbuch IV Nr. 134 S. 125. Erst einige Zeit nachher taucht der Oberstzunftmeister auf u. z. im Zusammenhang mit den Streitigkeiten der Psitticher und Sterner, He usler S.156 mit 118. Dabei wurde er offenbar geschaffen, um den unter Heinrich von Neuenburg für die bischöfliche Politik herangezogenen Zünften zu einem obersten, in die Rathsverfassung einfügbaren Organ zu verhelfen, Geering, Handel und Industrie der Stadt Basel, 1886 S. 37. Noch klarer liegen die Dinge in Zürich. Hier kannte die von Brun 1336 eingeführte Zunftverfassung nur ein en, lebenslänglichen Bürgermeister. Und dabei blieb es bis zum Tode von Bruns Nachfolger Rüdiger Manesse. Da sich dieser Unregelmälsigkeiten in der Verwaltung hatte zu Schulden kommen lassen (Bluntschli, Staats- und Rechtsgeschichte der Stadt und Landschaft Zürich, 2. Aufl. Zürich 1856 I S. 345 mit N. 25), beschlossen am 26. November 1383 die Räthe, Zunftmeister und die Zweihundert jährlich zwei Bürgermeister, jeden für ein halbes Jahr, zu 
werden ${ }^{1}$ ) - wenn endlich der süd- und mittelfranzösische centenarius, damit er als detachirter Curiale erklärt werden kann, seinen Namen deshalb erhalten haben muss, weil seit der Reichsgründung centenarius den gewählten Beamten bedeutete $^{2}$ )? Dass bei solcher Beweisführung auch das Uebrige keine Schwierigkeiten mehr bereitet, kann nicht verwundern ${ }^{3}$ ). Lebensäusserungen der Curie, die sie als nach wie vor in Kraft und Thätigkeit stehende Einrichtung bezeugten, hat man zwar nicht. Aber die Kölner Richerzeche weist eine auffallende Aehnlichkeit mit ihr auf, weil auch in ihr diejenigen Amtsleute die entscheidenden sind, die ihr Amt "verdient" haben"). Und dass die paar Formeln und Urkunden, welche in fränkischer Zeit die gesta municipalia und sonstige Theile des municipalen oder curialen Apparates, aber meist nur im Protocoll und $z$. Th. offensichtlich missverstanden erwähnen, lediglich mechanisch aus römischer Zeit herübergeschleppt wären, erklärt Mayer kurzweg für eine unsinnige Annahme ${ }^{5}$ ). Von der römischen Stadtbevölkerung seien nur

wählen, Zeller-Werdmüller, Die Zürcher Stadtbücher, Zürich 1899 I S. 275 f. mit ebenda S. 128 f., 241, 259. Es ergiebt sich hieraus für zwei Städte, dass von einer ursprünglichen Doppelbesetzung des Bürgermeisteramtes keine Rede sein kann, und dass die Einsetzung des zweiten Bürgermeisters, bezw. des Oberstzunftmeisters, wie übrigens jedenfalls auch die des ersten, bestimmte locale Ursachen hat. Aehnliches wird sich zweifellos auch für die übrigen Städte mehr oder weniger sicher feststellen lassen; über das allerdings eigenartige Bürgermeisterthum von Köln vgl. jetzt Lau, Entwicklung der communalen Verfassung und Verwaltung der Stadt Köln, Bonn 1898 S. 79 ff., 88 ff., 91. Damit fällt Mayers Erklärung des Bürgermeisteramtes dahin. Ist sie auch nur eine Einzelheit, so müssen doch derartige phantastische Aufstellungen, die von einem Mangel an nüchterner Kritik zeugen, nothwendig das Misstrauen des Lesers wachrufen und ihm die Frage nahelegen, ob nicht etwa anderwärts, wenn auch nicht so auffällig, Unterbau und Autbau an ähnlichen Mängeln litten.

1) I S. 313 ff. - ${ }^{2}$ ) I S. 301 f., 446, 515. - ${ }^{3}$ ) Ueber die libertas Romana von Selz vgl. Uhlirz, Histor. Vierteljahrsschrift II 1899, S. 257 f. mit Mayer I S. 304 N.4. - ") I S. 305 ff.; vgl. dazu jetzt La u a.a.0. S. $76 \mathrm{ff}$, Hansen in der Denkschrift zur Eröffnung der neuen Werftanlagen in Köln 1898, und zu beiden Knipping, Westdeutsche Ztschr. XVIII 1899 S. 81 f. - 5) „Dass man die Parteien zur Beurkundung an Behörden gewiesen hätte, welche gar nicht existirten, ist gerade so unsinnig, als wenn moderne Notariatsformulare von den alten Cent- 
die negociatores und die possessores in neue Rechtsverhältnisse übergetreten ${ }^{1}$ ), jene in die hansa, wobei freilich die Kaufmannsgenossenschaft auch weiterhin auf römisches Recht zurückgehe ${ }^{2}$ ), diese in die Vassallität. Die Lage der Handwerker dagegen blieb, und zwar im Norden wie im Süden, in fränkischer und späterer Zeit, im Wesentlichen dieselbe wie in römischer ${ }^{3}$ ). „Da wie dort ein freies, kein herrschaftliches Gewerbe, da wie dort die Unterstellung der einzelnen Handwerker unter die öffentliche Gewalt zu schweren Gewerbsabgaben und Diensten, da wie dort die Zusammenfassung des Gewerbes in Eidgenossenschaften (Bruderschaften, fraternitates), beidemale Zunftzwang und autonome Regulirung der gewerblichen Verhältnisse" ${ }^{4}$ ). So ist also auch das Zunftwesen glücklich unmittelbar auf das römische Recht zurückgeführt ${ }^{5}$ ).

Mayer stützt sich bei der Erörterung dieser Fragen, die erschöpfend nur unter Mitberücksichtigung des italienischen Materials könnten behandelt werden, wesentlich auf südfranzösische Quellen. Bald nach seinem Werk erschien die bis zum Schluss des 13. Jahrhunderts reichende Verfassungsgeschichte der Provence von Fritz Kiener ${ }^{6}$ ). Auch ihre Ergebnisse wird man nicht ohne Ausnahme gutheissen können ${ }^{7}$ ). Aber sie gewinnt den Leser alsbald durch ihre sichere historische Methode. Durchaus nicht ohne aufbauende Phantasie geschrieben, verwischt sie doch nirgends die quellenmälsige thatsächliche Lage der Dinge. Mit nüchterner Kritik werden blosse Vermuthungen und feststehende Thatsachen auseinandergehalten, und deutlich wird jeweilen

gerichten reden wollten “ I S. 296. Da bei einer auch nur einigermafsen objectiven Würdigung des damaligen Urkundeu- und Formelwesens und der Starrheit besonders der Protocolle die Unrichtigkeit des Vergleichs in die Augen springt, ist man der Mühe einer Widerlegung gegenüber dieser Behauptung enthoben.

1) I S. 337. - 2) I S. 337, II S. 236 ff., 245, Hansa S. 16. - ${ }^{\text {s) I }}$ S. 326 ff. - 4) I S. 330, 332, 336 f. - s) Für römisch wird ferner I S. 319 der ribuarische Gerichtsschreiber erklärt. ${ }^{6}$ ) Siehe oben S. 115 A. 1. $\left.{ }^{7}\right)$ Die Ausführungen S.. $59 \mathrm{ff}$. über den comes von Greg. Tur. Hist. Franc. VI c. 24 und über das Verhältniss von Patriciat und Comitat befriedigen nicht, und auch der mehrfache Bedeutungswandel von vicedominus $\$$. 41, 63, 66, 116 erregt $Z_{\text {weifel. }}$ 
ein neuer Einschlag hervorgehoben, sodass man ein anschauliches Bild vom Werden und allmähligen Wachsthum der mittelalterlichen Verfassungseinrichtungen erhält. Es ist interessant, Kieners Ergebnisse für die Geschichte der provençalischen Consulatsverfassung mit denen Mayers für Südfrankreich überhaupt zu vergleichen. Das keineswegs überraschende Ergebniss ist, dass bereits in ostgothischer Zeit die Curie in der Provence in bedenklichen Verfall gerathen war ${ }^{1}$ ), und dass, nachdem die Franken, wie schon vorher die Ostgothen, gerade in den Städten sich festgesetzt hatten ${ }^{2}$ ), diese in die von den Merowingern neu geordnete ${ }^{3}$ ) und von den Karolingern umgestaltete ${ }^{4}$ ) allgemeine Landesverfassung hineinbezogen wurden ${ }^{5}$ ). Bis in die erste Hälfte des 12. Jahrhunderts fehlt nicht nur jedes Zeugniss, sondern auch der Raum für eine besondere Communalverfassung ${ }^{6}$ ). Da erst erhebt sich, zuerst 1128 in Marseille, besonders deutlich aber und durchsichtig 1131 in Arles, die geschworene Eidgenossenschaft des älteren Consulats ${ }^{7}$ ), das Kind einer neuen Zeit, neuer Verhältnisse, gerade in seiner inneren Einrichtung eine durchaus local ausgeprägte Neubildung ${ }^{8}$ ).

VI.

Auch zur Kritik dessen, was Mayer über die Organisation der öffentlichen Verbände und Behörden ausführt, trägt Kieners Einzeluntersuchung, wenigstens soweit als die südfranzösischen Territorien in Frage stehen, manches bei.

Da kommt zunächst der comes in Betracht, der nach

1) Kiener S. 14. - ${ }^{2}$ ) Dersel be S. 9, 28. - ${ }^{3}$ ) Ebenda S. $52 \mathrm{ff.}-$ 4) a. a. O. S. $113 \mathrm{ff} ., 135$. - 5) Kiener S. 68 ff. - ") Ebenda. - 7) Derselbe S. $163-210$, von da ab über die neuen Consulate. $-{ }^{8}$ ) In glänzender Ausführung hat Kiener namentlich für Arles die Voraussetzungen, die Entstehungsgeschichte und das Wesen des Consulats dargethan. Aus ihm S. 192 ff., 218, 220 (221), 224, 233 lernt man namentlich erkennen, wie die übrigens durchaus nicht allenthalben ursprüngliche und dauernd beibehaltene Vierzahl der consules durch locale oder andere Zufälligkeiten bedingt war. Dadurch ist für die Provence Mayers Theorie der letzte Halt entzogen, was Mayer selber, der aus Kieners Buch vor allem den Nachweis weiterer Belege für die Vierzahl aufgenommen hat (Deutsche Litteraturzeitung 1899, 9.Dec., Sp. 1881), freilich nicht zugeben will. 
Mayer nicht auf den Grafen zurückgeht ${ }^{1}$ ) und erst im Laufe des 8. Jahrhunderts mit diesem identisch wird ${ }^{2}$ ). Er soll vom römischen comes civitatis abstammen ${ }^{3}$ ). Allerdings besass dieser nach dem bekannten Grundsatz der diocletianischen Verfassung von der Trennung der Militär- und der Civilgewalt nur militärische Befugnisse; er war Stadtcommandant ${ }^{4}$ ). Aber im Reiche des Syagrius habe er die bürgerliche Gewalt hinzuerworben ${ }^{5}$ ), und so sei er, während der Behördenorganismus des Reichsrechtes wegfiel, als ein Stück der Organisation der Civitas von den Franken übernommen worden. In den westgothischen Gebieten dagegen sei die Verbindung der beiden Gewalten in der Weise hergestellt worden, dass der comes im Gericht des iudex (vicarius) civitatis (später auch potestas) ${ }^{6}$ ) erschien, dessen Amt, meist von Klerikern versehen, auf eine vom rector provinciae für die einzelne civitas geschaffene Vertretung zurü.ckzuführen sei ${ }^{7}$ ). Dagegen haben nach Kiener die Franken in der Provence die Scheidung von Civil- und Militärgewalt nicht nur noch vorgefunden, sondern sogar zunächst auch beibehalten ${ }^{8}$ ). Thre Aufhebung wird von ihm in einleuchtender Begründung mit der Heranziehung der Romanen zum Heerdienst erklärt ${ }^{9}$ ).

Ich übergehe den vicarius locorum ${ }^{10}$ ), der nach Mayer der Abkömmling des römischen vicarius numeri, eines für die Verfolgung von Räubern bestellten Offiziers ist ${ }^{11}$ ), und durch die Landfriedensgesetzgebung an Stelle des Königsbanns Blutgerichtsbarkeit erhalten hat ${ }^{12}$ ), sowie den vice-

1) I S. 338 mit N. 2. Brunner, Deutsche Rechtsgeschichte II S. $164 \mathrm{ff}$, sieht in ihm bekanntlich den neufränkischen Grafen, dem sich dann wiederum der altfränkische angeglichen hat. $-{ }^{2}$ ) I S. 340.3) Mayer betont wiederholt I S. 303 und 338, dass das Verhältniss zur Centralgewalt für den Grafen der fränkischen Zeit dasselbe sei, wie es für den comes civitatis war, indem auch dieser $1 / \mathrm{s}$ der Gefälle behielt, während er $2 / 3$ abzuliefern hatte. — 4) I S. 304, 339. - 5) I S. 339 . •) I S. 345 ; vgl. dazu Kiener S. 221 und Mayer, Deutsche Litteratur-

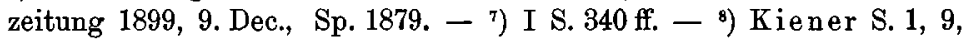
20, 50. - ${ }^{9}$ ) Ebenda S. $50 \mathrm{ff}$. Wir erinnern uns daran, dass Mayer zwischen Seine und Loire die Romanen früher heerpflichtig werden lässt als anderswo, oben S. 139 A. 4. Das würde dann auch das Vorangehen dieser Gegenden mit der Comitatsverfassung erklären. ${ }^{10}$ ) I S. 348 ff. - ${ }^{11}$ ) I S. 363 ff.; dazu Kiener S. 118 ff. - ${ }^{12}$ ) I S. 353. 
comes ${ }^{1}$ ), den Vertreter des Grafen in seiner persönlichen Gerichtsbarkeit ${ }^{2}$ ), der es da, wo ein Graf mehreren Grafschaften vorstand, in dieser Vertretung bis zur Hochgerichtsbarkeit brachte ${ }^{3}$ ), und endlich den castellan us ${ }^{4}$ ) (tribunus) ${ }^{5}$ ) sowie einige andere Beamte dieser romanischen Gebiete, um mich der Organisation der germanischen Verbände zuzuwenden.

In dreifacher Abstufung reichen sie in die Urzeit zurück, als Gemeinde, als Hundertschaftsverband und als Völkerschaft.

Darin, dass er die Gemein de als Zehend, Zeche, (Ur-) Kirchspiel schon dem ältesten öffentlichen Recht zuweist ${ }^{6}$ ), stellt sich Mayer wiederum in entschiedenen Gegensatz zur herrschenden Meinung, die in ihr eine spätere Bildung sieht ${ }^{7}$ ). Ursprünglich eine Verbindung von zehn Familien der kleinen Freien ${ }^{8}$ ) mit einem gewählten, später oft erblichen Vorstand (decanus, Holzgraf, Hunne, Weibel, Bauermeister) ${ }^{9}$ ) und einem Rath (Heimburger, Heimraden) ${ }^{10}$ ) hat sie vor allem wirthschaftliche Functionen ${ }^{11}$ ), trägt sie die Gesammt(Friedens)bürgschaft ${ }^{12}$, und ist sie Inhaberin von Gerichtsbarkeit $\left.{ }^{13}\right)$.

Von dem Bild, das Mayer von der nach ihm in die Jäger- und Hirtenzeit zurückreichenden ${ }^{14}$ ), ursprünglich einen Heeresverband bedeutenden ${ }^{15}$ ) Hunder tsch af t (Go) ${ }^{16}$ ) sich macht, haben wir schon unter II und III wesentliche Züge kennen gelernt. Hier ist noch nachzutragen, dass die Hundertschaft ausser der Verwaltung der Allmende ${ }^{17}$ ), derjenigen Function, die ihr am längsten blieb, auch Gerichtsbarkeit hatte, ja, wie alsbald sich zeigen wird, als wichtigster Gerichtsverband des Volksrechtes erschien. Ihr gewählter Vorsteher war der Centenar oder Cent(Go)graf ${ }^{18}$ ), dem es mancherorts gelang, sein Amt in ein Erbamt umzuwandeln ${ }^{19}$ )

1) I S. 355. ff. - ${ }^{2}$ ) I S. 357, 360; vgl. dazu Kiener S. $122 \mathrm{ff.}-$ 3) I S. 359 f. - ${ }^{4}$ ) I S. 360 ff. - ${ }^{5}$ ) I S. $366 .-{ }^{6}$ ) I S. 484, 511, 512, 514. -

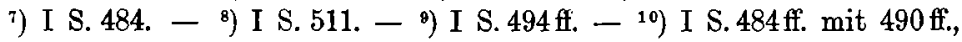
514. - ${ }^{11}$ ) I S. $515 \mathrm{ff} .{ }^{12}$ ) I S. 519. Die gemeingermanische Gesammtbürgschaft Mösers, von Waitz, Verfassungsgeschichte $I^{3}$ S. $454 \mathrm{ff}$., wie es schien, endgültig beseitigt, ersteht also bei $M$ ay er von neuem. 13) I S. $517 \mathrm{ff} ., 375 . \quad-{ }^{14}$ ) I S. 434 mit N. 2, 414. - ${ }^{15}$ ) I S. $434 .-$ $\left.{ }^{18}\right)$ I S. $435 \mathrm{f} ., 442 .{ }^{17}$ ) I S. $436 \mathrm{ff} .-{ }^{18}$ ) I S. $445 \mathrm{ff} .-{ }^{19}$ ) I S.447ff. Ueber 
Solche Allodialcentgrafen oder Allodialherren wurden freie Herren genannt ${ }^{1}$ ); wie sie weiterhin zu dem Titel Barone kamen, ergiebt sich aus dem Früheren ${ }^{2}$ ).

Am schwersten erkennbar ist späterhin der oberste Verband, die durch die amtsrechtliche Grafschaft überschattete Völkerschaft ${ }^{3}$ ). Auch sie hatte ihren Vorsteher, dessen Abkömmlinge der fränkische Tungin ${ }^{4}$ ), der bairische iudex, der sächsische Grafschaftsschultheiss und der nordalbingische Overbote waren ${ }^{5}$ ). Sie war also ebenfalls Gerichtsverband.

Wie gestaltete sich nun das Verhältniss dieser verschiedenen Gerichtsbarkeiten, was ergibt sich aus Mayers Darstellung über die Geschichte des Gerichtswesens und der Gerichtsverfassung? Man muss unterscheiden zwischen dem rein volksrechtlichen Zustand und zwischen der Neugestaltung der Gerichtsverhältnisse durch das königliche Amtsrecht seit der Reichsgründung.

Der hervorstechendste Zug im Bilde des ältesten Gerichtswesens ist nach Mayer die Autonomie der Hundertschaftsgerichte. Es gab nicht ein oberstes Gericht, an das der Rechtszug vom Gerichte der Hundertschaft gegeben war ${ }^{6}$ ), und die Hundertschaften stellten auch nicht die Gerichtsgemeinde für das Gericht eines grösseren Bezirkes ${ }^{7}$ ). Vielmehr war jede Hundertschaft souverän und gewissermafsen das Gericht schlechthin, dem alle Gerichtsbarkeit,

den Gegensatz der aristokratischen (erblichen oder durch Wahl nur der Erfexen besetzten) Gografschaft und der durch Wahl der Bauern vergebenen siehe I S. 447 mit N. 42.

1) I S. 452. - ${ }^{2}$ ) Vgl. oben S. 145. - $^{3}$ ) I S. $471 \mathrm{ff.} \mathrm{-} \mathrm{4)} \mathrm{I} \mathrm{S.} \mathrm{483.} \mathrm{-}$ 5) I S. $476 \mathrm{f}$. - $)$ Die kämpfliche Schelte, d. h. die alte ursprüngliche Form, ein Urtheil zu schelten, muss aufgekommen sein zu einer Zeit, wo das betreffende Gericht - und nach Mayer kann das nur das Hundertschaftsgericht gewesen sein - das höchste Gericht war. Die Klage gegen Rechtsbeugung dagegen wird gegeben, nachdem über das bisher souveräne Gericht ein höheres getreten ist II S. 412; vgl. ebenda S. 111 mit $108 \mathrm{ff.}$ - 7) Nur ausnahmsweise hielt wohl da, wo mehrere Civitates zu einem Concilium vereinigt waren, der Völkerschaftsrichter in ähnlicher Weise in den Hundertschaften Gericht wie später der fränkische Graf, und nur dann ergab sich das aus Tacitus, Germania c. 12 bekannte Bild. I S. 477. 
von der geringfügigen Gemeindegerichtsbarkeit ${ }^{1}$ ) und den etwa dem Völkerschaftsgericht vorbehaltenen besonderen Vergehen gegen die Gesammtheit abgesehen, zukommt, also auch die Blutgerichtsbarkeit ${ }^{2}$ ). Dieses Hundertschaftsgericht aber tritt, wie alle germanischen Gerichte, meistens als Vollgericht zusammen, erst in späterer Zeit häufiger als Schöffengericht. Nur das Vollgericht kann über das Blut und über Liegenschaftsstreitigkeiten ${ }^{3}$ ) sowie über nicht gewettete Schulden ${ }^{4}$ ) urtheilen. Ueber das Blut richtet es stets nur als von dem Verletzten oder seiner Sippe gebotenes Ding; "die Quellen kenmen nur ein ausserordentliches Zusammenrufen der Gemeinde zum Blutgericht" ${ }^{5}$ ). Als echtes Ding dagegen tagt es von 6 zu 6 Wochen ${ }^{6}$ ) für volksrechtliche Rügesachen ${ }^{7}$ ), Immobiliarprocesse und Streitigkeiten um nicht gewettete Schuld ${ }^{8}$ ), von 14 zu 14 Tagen $^{9}$ ), hier aber nur facultativ als Vollgericht ${ }^{10}$ ), über Fahrhabestreitigkeiten und Schuldsachen ${ }^{11}$ ).

In diesen Zustand greift nun bald nach der Reichsgründung, jedenfalls aber vor Karl dem Grossen ${ }^{12}$ ) das königliche Amtsrecht ein. Das Grosskönigthum strebt darnach, alle Autonomie zu brechen und vor Allem die Hochgerichtsbarkeit an sich zu ziehen ${ }^{13}$ ). In der Völkerschaft

1) I S. 243 f., $249,375$. - $^{2}$ I S S. $437,444,378,474 .-{ }^{3}$ ) I S. $369 \mathrm{ff}$. - 4) I S. 376. Nicht gewettete Schulden dürfen ausserhalb des Vollgerichts nur geltend gemacht werden, wenn ein Compromiss stattgefunden hat. Nichts anderes als solch ein Compromiss ist der Klageinsatz (delatura, destrictus) des Klägers und der Gegeneinsatz des Beklagten; man hat die durch Pfandsetzung gesicherte Unterliegensbusse als eine dem sacramentum des römischen Legisactionenprocesses ähnliche Einrichtung anzusehen. I S. $151 \mathrm{ff}$ - ${ }^{5}$ ) I S. $370 .{ }^{\text {b) }}$ I. S. $372 \mathrm{f}$. Später tritt dies Sechswochending ausser in Sachsen und Ostfranken nur noch im Fristenwesen hervor. Vgl. auch oben S. 134 A. 4. - 7) I S. 243 f., 259, 374. $-{ }^{8}$ ) I S. 374. - ${ }^{9}$ ) I S. 446 f., 373: „Diese Fristen von sechs zu sechs Wochen oder gar von 14 zu 14 'Tagen sind in einer ackerbauenden Gesellschaft viel zu kurz. So muss die derart befristete Gerichtsversammlung bereits aus der Jäger- und Hirtenzeit übernommen sein, wo die einzelnen beweglicher und ungebundener waren". 10) I S. 447. - ") I S. 446: „Im ganzen Mittelalter ist das Centgrafengericht für Obligationen- und Mobiliarsachenrecht competent." S.372. ${ }^{12}$ ) I S. 456. - ${ }^{13}$ ) I S, 378, 454 ff. Ueber die Stellung des fränkischen Grosskönigthums zur Autonomie der Gemeinden und bäuerlichen Gilden siehe I S. 355,513 f., 534, II S. 401. 
tritt der königliche Graf neben den einheimischen Richter der Völkerschaft ${ }^{1}$ ), der sich ihm unterordnen und froh sein muss, wenn er unter dem Grafen als Vorsitzender des Grafengerichts sich $\mathrm{zu}$ behaupten vermag, wie dies dem bairischen iudex gelang ${ }^{2}$ ). Eine wahre Umwälzung brachte das königliche Amtsrecht im Bereiche der Hundertschaft mit sich.

Von dem einen Ziele, das in der Schaffung eines abhängigen Beamtenthums im Hundertschaftsbezirk bestand, soll hier nicht weiter die Rede $\operatorname{sein}^{3}$ ); es wurde dadurch erreicht, dass der König dem volksrechtlichen Hundertschaftsvorstand, zumal da, wo er nicht Allodialherr geworden war, die bereits im salischen Recht als sagibarones bezeugten mehreren Schultheissen zur Seite setzte ${ }^{4}$ ), wenn es nicht gelang, den Centenar selbst zum Regierungsbeamten und zum Schultheissen zu machen ${ }^{5}$ ).

Die Hauptmühe kostete die Aneignung der bisher hundertschaftlichen Hochgerichtsbarkeit. Nur dabei blieb es auch weiterhin, dass bloss im Vollgericht über das Blut sollte gesprochen werden können ${ }^{6}$ ). Dagegen verlor jetzt der Verletzte das Recht, die Genossen gegen den Missethäter durch das Schwert oder den Hut aufzubieten ${ }^{7}$ ); der Graf allein versammelt die Gerichtsgemeinde. Zur Rüge der Königsbannfälle hatte er, zu dessen ursprünglichsten Amtsaufgaben ja die Eintreibung der Brüchten und insbesondere des Königsbanns gehörte ${ }^{8}$ ), schon bisher seine drei Tage abgehalten ${ }^{9}$ ). Diese tria placita ${ }^{10}$ ) des Grafen sind zum Mindesten seit dem Beginn der Regierung Karls des Grossen die einzigen Volldinge ${ }^{11}$ ). Damit ist dem Hundertschaftsvorsteher die Blutgerichtsbarkeit entzogen ${ }^{12}$ ). Die Versammlungen aber, deren sich der Graf für seine drei Tagungen in Blutsachen bediente, konnten

1) I S. 477. - ${ }^{2}$ ) Ebenda. - ${ }^{3}$ ) I. S. $454 . \quad-{ }^{4}$ ) I S. 460 ff., 467, 264. Ueber die Schultheissen der Goe im Sachsenspiegel siehe I S. 456 N. 59. - ${ }^{8}$ ) I S. $463 \mathrm{ff.}$. $466 .{ }^{\theta}$ ) I S. $454 .{ }^{7}$ ) I S. 377; vgl. $371 .-$ 8) I S. 263 f. - ${ }^{9}$ ) I S. 377 f., 259 ff., 372. Dass die drei Placita nicht auf die ungebotenen Dinge des Volksrechtes zurückgehen, sondern auf Versammlungen des Amtsrechtes, erhelle auch daraus, dass sie von jedem Hofbesitzer, auch vom unfreien besucht werden mussten. - ${ }^{10}$ ) $\mathrm{Zu}$ denen dann noch jährlich die eine stille Wahrheit gegen die Gewohnheitsverbrecher kommt I S. 274 ff., 377. - 11) I S. 377, 378. 12) I S. $378,446,481$. 
die Völkerschafts(Grafschafts)versammlungen sein $\left.{ }^{1}\right)$. Wo sich jedoch solche nicht erhalten hatten oder nicht einbürgerten, da kam der Graf in die Hundertschaft, um in ihr, aber für die Grafschaft, Gericht zu halten ${ }^{2}$ ). So wurden die bisher selbstständigen Hundertschaftsgerichte dem Grafschaftsorganismus eingefügt, und ward das Herumreisen des Grafen-Richters bei den Hundertschaften seiner Grafschaft Regel. Alle übrigen bisherigen Vollgerichte fielen weg $^{3}$ ) und wurden ersetzt durch Schöffengerichte ${ }^{4}$ ). Solche gab es schon vorher auf allen drei Stufen, in Grafschaft, Hundertschaft uud Gemeinde ${ }^{5}$ ). Jetzt wurden sie die Regelgerichte ${ }^{6}$ ), welchen namentlich die Immobiliargerichtsbarkeit zustand, "die ja nach der mittelalterlichen Auffassung auch die Streitigkeiten des Familien- und Erbrechts befasst" "). Dabei gehört zum Wesen des Schöffen nichts weiter, als dass er „ein ständiger Urtheilsfinder ist, im Gegensatz zu dem Urtheilsfinder, der für den einzelnen Fall aus der gesammten Gerichtsgemeinde auftritt" ${ }^{4}$ ), keinieswegs also Lebenslänglichkeit und obrigkeitliche Ernennung. Einzig die Grafschaftsschöffen waren eine Zeit lang lebenslänglich und von Obrigkeits wegen bestellt. Aber gerade bei ihnen siegte bald die Erblichkeit, und nach dem Aussterben der schöffenbaren Familien traten die nobiles überhaupt an ihre Stelle ${ }^{9}$ ). „Dass Karl der Grosse die Schöffen eingeführt habe, ist eine Hypothese ohne Stütze" ${ }^{10}$ ).

1) I S. $454 \mathrm{f}$, $478 \mathrm{ff}$., $482 \mathrm{f}$. In den romanischen Sïden wurde diese Versammlung als solche der franci, später der Ritterlichen übertragen. - ${ }^{2}$ ) I S. 455, 459, 477, 480 f. Nach dem mittleren und südlichen Frankreich wurde die germanische Hundertschaft nicht verpflanzt. Dort wird darum die Hochgerichtsbarkeit ohne Weiteres an die Grafschaftsassise geknüpft I S. 444 f., 482 f., vgl. dazu S. 455 . 3) I S. 378: „So sind die Versammlungen, welche zu Gunsten des Königs im Jahre zwei- bis dreimal aufgeboten werden, allein erhalten geblieben und dienen, weil sie eben Vollgerichte sind, auch als Criminalgerichte; die übrigen ungebotenen Dinge des Volksrechts sind wenigstens für das Reichsrecht gefallen." - ") I S.407, 377. - 5) I S. 402 ff., 307, 393, 396, 401. Ueber die Verbreitung des Schöffeninstituts I S. $391 \mathrm{ff}$., 395, $307 \mathrm{ff}$. Ueber Schöffen im Königsgericht I S. 389 f., II S. $346 \mathrm{f}$. 6) I S. 384. - ${ }^{7}$ ) I S. 407 . Ueber die Confiscationsurtheile, die von Grafschaftsschöffen ausgehen I S. 408. - ') I S. 307, 404. - ') I S. $402 \mathrm{f}$, 307, 404. Vgl. oben S. 138. - ${ }^{10}$ ) I S. $405 \mathrm{f}$.

Zeitschrift für Rechtsgeschichte. XXI. Germ. Abth. 
Die fränkischen Grundlagen der Gerichtsverhältnisse wurden in nachfränkischer Zeit nicht aufgegeben, aber erheblich eingeschränkt. Hie und da werden Schöffengerichte zu Blutgerichten ${ }^{1}$ ). Und es bildete sich, wenn auch aus verschiedener Wurzel, eine mittlere Gerichtsbarkeit heraus, welche alle Gerichtsbarkeit, also auch die über Liegenschaften und die Bestrafung der Räuber, mit einziger Ausnahme der Blutgerichtsbarkeit im engern Sinne umfasste ${ }^{2}$ ), und in Frankreich namentlich dem vicarius oder ballivus ${ }^{3}$ ), in Deutschland vornehmlich einem Vogt genannten $\mathrm{Be}$ amten ${ }^{4}$ ) zustand. Vor Allem aber gehen die Gerichte, d. h. das Amtseinkommen, die Gefälle ${ }^{5}$ ), in Südfrankreich als vererbliches Allod ${ }^{6}$ ), anderswo, namentlich in Deutschland, als Lehen ${ }^{7}$ ) an die Fürsten, insbesondere an die Herzöge, über. Nur die Uebertragung des Amtes, die Ausübungsermächtigung $^{8}$ ), deren bedarf, wer Blutgerichtsbarkeit zu Eigen hat ${ }^{9}$ ) oder mit ihr beliehen ist ${ }^{10}$ ), nur die behält das Königthum noch geraume Zeit. Sie erfolgt durch die zu keiner Mannschaft verpflichtende und deshalb auch vom Thronfall nicht berührte Bannleihe ${ }^{11}$, in der man, weil der Graf anfünglich der Eintreiber der Bannbrüche war, dessen ursprüngliche Bestallungsform zu erblicken hat ${ }^{12}$ ). Die Entwickelung, die den Grafen zum Hochrichter machte, zog die Umdeutung der Bannleihe auf die Gewalt, über das Blut zu richten, nach sich. Um ihretwillen erschien die Bannleihe später als Uebertragung des Blutrichteramtes.

\section{VII.}

In der Gewalt über die Unfreien und in der Hausherrschaft, deren Erweiterung zur Gefolgschaft und Gesindschaft wir ja bereits kennen lernten ${ }^{\mathbf{1 3}}$ ), wurzelt nach Mayer ${ }^{14}$ ) alle

1) I S. 408 f., $\left.464,260 .-{ }^{2}\right)$ I S. 351 , II S. $356 .-{ }^{3}$ ) I S. $348 \mathrm{ff.}$,

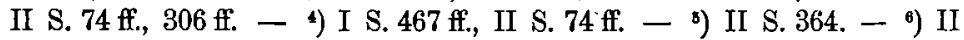

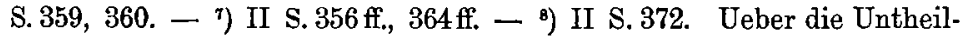
barkeit der Grafschaft und gegen die Vorstellung, dass in nachfränkischer Zeit die Grafschaftsbezirke durch Theilung stark vermehrt worden seien, II S. $373 \mathrm{ff} .{ }^{-9}$ ) I S. 358 f., II S. $360,407 .{ }^{10}$ ) II S. $350 \mathrm{ff.}-$ $\left.{ }^{11}\right)$ II S. $350 .{ }^{12}$ ) I S. $263 \mathrm{f}$., II S. $353 .{ }^{13}$ ) oben S. $141 \mathrm{ff}$, $147 \mathrm{ff}$. 14 II S. $3 \mathrm{ff}$. 
Herrschaft. Ueber Leute, die weder Eigen des Herren waren, noch seinem Haus angehörten, gab es also ursprünglich eine solche nicht ${ }^{1}$ ). Die Niederlassung auf fremdem Grund und Boden zog für dessen Eigenthümer keine persönliche Gewalt über die Niedergelassenen nach sich ${ }^{2}$ ). Lediglich aus dem Rechtsgrund seines Eigenthums hatte der Grundherr auch noch später keine Gerichtsbarkeit über die freien Pächter. „Die niedere Gerichtsbarkeit, die er besitzt, erklärt sich dadurch, dass die Gemeindegerichtsbarkeit grundherrlicher Dörfer unter des Grundherrn Einfluss steht ${ }^{\text {( } 3)}$ ). Auf deutschem Boden konnte die Pacht nur bei ausdrücklichem Eintritt in die Unfreiheit eine persönliche Gewalt begründen ${ }^{4}$ ). Aber auch in Gallien sind die Colonen mit ihren Gütern durch einen Rechtsact - wahrscheinlich durch Ergebung in das Patrocinium des gallischen Provinzialrechts in die Gewalt der Grundherren gekommen ${ }^{5}$ ). Etwas Ursprüngliches ist somit die Grundherrschaft nirgends ${ }^{6}$ ).

Die Gewalt über die Unfreien äussert sich namentlich in der zu einer Blutgerichtsbarkeit gewordenen Tödtungsbefugniss ${ }^{7}$ ), als Recht auf Geschlechtsgenuss der unfreien

1) II S. 36 ff. - 2) II S. $38 .-$ 3) II S. 47 f. - ${ }^{\text {4) }}$ II S. $43,40 .-$ 5) II S. 53. Das in Zeitpacht gegebene Kleingut, hospitium, „muss schon an der Grenze der römischen und der fränkischen Zeit etwas thatsächlich Erbliches gewesen sein, und doch hat das noch bis in das spätere Mittelalter nicht zu einer nothwendigen Unterwerfung des hospes unter die persönliche Gewalt des Herren geführt." II S. 53, 51. Also kann, wenigstens für Gallien, der Colonat, bei dem der Colon schon seit der spätrömischen Zeit erblich gebunden ist und in fränkischer erblich gebunden blieb, nicht aus einer thatsächlich erblich gewordenen Zeitpacht erklärt werden. Sonst hätte der Pächter des Kleinguts erst recht in solche Abbängigkeit gerathen müssen. Vielmehr können in Gallien die coloni mit ihren Besitzungen von Haus aus dem Herrn gar nicht gehört haben, müssen also durch Ergebung adscripticii geworden sein. II S. $53 \mathrm{ff}$ - - Ueberhaupt war die gallischrömische Betriebsform die herrschaftliche Eigenwirthschaft. Als römisches Erbe hat das eapitulare de villis den von ihm so stark betonten Eigenbau übernommen, während, ursprünglich und noch lange, deutsch die Vereinigung mehrerer Latenhufen und Hufen Unfreier unter einem Herrn war. II S. 54 f. - ${ }^{\circ}$ II S. 38. - 7) II S. 4 ff. Diese tritt also in Concurrenz zur landrechtlichen Hochgerichtsbarkeit. Doch fehlt eine scharfe Abgrenzung II S. 404. 
Frauen ${ }^{1}$ ), welches in das Recht der ersten Nacht ${ }^{2}$ ) oder auf Heiratsabgaben ${ }^{3}$ ) ausmündet, in dem Ausschluss der Freizügigkeit ${ }^{4}$ ) und als Recht am Vermögen ${ }^{5}$ ). In letzterer Hinsicht führte bei Lebzeiten des Knechtes die Zuweisung eines Hofes zu selbständiger Landwirthschaft ${ }^{6}$ ) oder auch nur einer Sölde ohne Mansus (Hagestolze) ${ }^{7}$ ) zu einer Beschränkung des Herrenrechtes, die auch beim Tode des Unfreien in thatsächlicher oder hofrechtlicher Erblichkeit des Gutes ${ }^{8}$ ) und im Butheils- ${ }^{9}$ ) oder im Besthauptsrecht ${ }^{10}$ ) am beweglichen Nachlass zu Tage trat.

Durch Mannschaft ${ }^{11}$ ), die nach den nördlichen, namentlich nach den deutschen Quellen zwar zum abhängigen Mann macht, aber die Freiheit unangetastet lässt ${ }^{12}$ ), während sie nach südfranzösischem Recht die Unfreiheit nach sich zieht ${ }^{13}$ ), ergeben sich Freie in das mitium oder die familia ${ }^{14}$ ) eines Herrn. Sie haben Theil an dessen Schutz zusammen mit den coloni und fiscalini ${ }^{15}$ ), heissen aber mitici schlechthin, weil sie ausserhalb des Herrenlandes sitzen, vom Herren nichts zu Lehen haben, und weil bei ihnen die Beziehung zum Herrn in dem durch Zins gefesteten Schutzverhältniss eben dem mitium - sich erschöpft ${ }^{16}$ ). Inframitici sind dann weiter die am Ort, forasmitici oder forenses die auswärts Wohnenden ${ }^{17}$ ).

Diese private Herrschaft mit ihrem von Hause aus absoluten Gewaltrecht erfuhr nun aber im Laufe der Zeit eine rechtliche Begrenzung und Milderung ${ }^{18}$ ). Schon die damals herrschende Naturalwirthschaft brachte eine solche in gewissem Sinne mit $\operatorname{sich}^{19}$ ). Noch mehr aber der Wille der Gewaltunterworfenen. Dieser machte sich in der Weise geltend, dass bei Verfügungen des Herrn über ein bestimmtes Gut dessen Bauern ein Zustimmungsrecht erwarben, und bei

1) II S. 9. $-{ }^{2}$ ) II S. 8: „Es ist selber nichts als ein schlechter Spass, wenn man diese sehr bestimmt lautenden Nachrichten (über das ius primae noctis) als einen Scherz bezeichnet." - 3) II S. 7. - 4) II

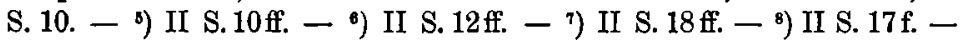
$\left.{ }^{9}\right)$ II S. 22 ff. - ${ }^{10}$ ) II S. 24 ff. Das Besthauptrecht sei nicht eine Abschwächung des Butheils, sondern ebenso alt und vielleicht ursprüngliches Litenrecht. - 11) II S. 35. - 12) a. a. O. - 13) ebenda; vgl. oben S. 144. - ${ }^{14}$ ) II S. $32 . \quad-{ }^{16}$ ) ebenda; vgl. oben S. 125 A. 8. ${ }^{18)}$ ebenda. $-{ }^{17}$ ) II S. $32,30 .-{ }^{18}$ ) II S. 55 ff. $-{ }^{19}$ ) II S. 56. 
Angelegenheiten, die den Herrn und die Centralverwaltung betrafen, die hohen Beamten des Hofs, die Ministerialen, zuzustimmen hatten ${ }^{1}$ ). Ausserdem war ja die herrschaftliche Gewalt dem gesammten Rechtsverband eingeordnet ${ }^{2}$ ). „Das deutsche Recht liess gar keine Beschränkung des öffentlichen Rechtes durch die Grundherrschaft $\mathrm{zu}^{\text {( }}{ }^{3}$ ), wie z. B. der unfreie mansionarius, weil er eigen Feuer und Rauch hatte, durchaus heer-, königszins- und dingpflichtig war ${ }^{4}$ ). Das musste natürlich den rechtlichen Ausbau der Herrschaft fördern. Die öffentliche Gemeindeverfassung ${ }^{5}$ ) und das geregelte Gerichtswesen des öffentlichen Rechtes hielten Einzug. Ganz besonders da, wo die Herrschaft durch die aus dem römischen Recht übernommene Immunität ${ }^{6}$ ) auf ein Element des öffentlichen Rechtes sich stützte ${ }^{7}$ ), und die Entscheidungsgewalt des Herrn wahre Gerichtsgewalt wurde ${ }^{8}$ ), welche in den geistlichen Herrschaften durch Verleihung von Seiten der deutschen Könige zur Hochgerichtsbarkeit über alle Criminaldelicte sich erweiterte ${ }^{9}$ ).

Nach aussen trat die Organisation der Herrschaft als Vogtei auf; die Vögte dienten zur Verantwortung der Unterthanen im öffentlichen Gericht. Doch verdankten sie nicht diesem Zweck, ihren Ursprung, sondern der aus dem römischen Recht übernommenen Befugniss der Barone, sich vor Gericht vertreten zu lassen ${ }^{10}$ ).

Die unteren Stufen der für die innere Herrschaftsverwaltung bestimmten Behördenorganisation werden gebildet durch die Meier (maiores, villici, bajuli) - im französischen Westen oder bei einfacheren Verhältnissen zugleich Wirthschafts- und Gerichtsbeamte, im deutschen Osten und überhaupt auf grösseren Gütern nur das erstere, mit einem Schultheissen oder Ammann für das Gericht zur Seite ${ }^{11}$ ).

Reicher entwickelt ist das Hofbeamtenthu $\mathrm{m}^{12}$ ). Die einzelnen am Hofe wohnenden oder bei Hof gerade anwesenden Vassallen und Ministerialen bildeten namentlich

1) II S. 56 ff. - ${ }^{2}$ ) II S. 83. - $^{3}$ II S. $64 .-{ }^{4}$ ) II S. 71. - ${ }^{\text {s) I }}$

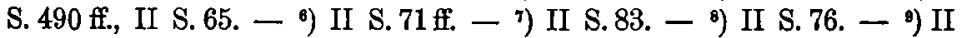
S. $77 . \quad{ }^{10}$ ) II S. 290 ff., 150, oben S. 144. - ${ }^{11}$ ) II S. 295 ff. - ${ }^{12}$ ) II S. $317 \mathrm{ff}$. 
auch für die Rechtsprechung den Rath des Herrn ${ }^{1}$ ). Dabei zeigt sich jedoch ein wichtiger Unterschied zwischen dem Westen und dem Osten, indem dort formirte Rathscollegien (Parlament, Scaccarium) sich ausschieden ${ }^{2}$ ), in denen weltliche Räthe neben geistlichen nach Gesichtspunkten des staatlichen Interesses die Staatsgeschäfte führten, während der Mangel solcher ständiger Collegialbehörden in Deutschland ${ }^{3}$ ) die Staatsverwaltung geistlichen Bureaukraten, den Klerikern der Kanzlei, auslieferte, woran schliesslich das deutsche Königthum zu Grunde ging ${ }^{4}$ ). Auch hinsichtlich der einzelnen Beamtungen stechen übrigens die deutschen und die französischen Höfe von einander ab. Zwar die vier germanischen Hofämter des Schenken, Truchsessen, Kämmerers und Marschalls ${ }^{5}$ ), sowie das fünfte, spätere des Vicedominus ${ }^{6}$ ) oder Hofmeisters ${ }^{7}$ ), das theils der Vermögensverwaltung diente, theils und vor Allem für die Gerichtsbarkeit über die von den einzelnen Grossbeamten Eximirten da war sie finden sich gleich dem Cancellariat hüben und drüben. Aber in Frankreich behauptete sich, weil der französische Hof auf den capetingischen zurückging und die Fortentwickelung der karolingischen Hoforganisation unterblieb, die Gleichordnung der einzelnen grossen Hofämter, sodass diese auch weiterhin von vornehmen Freien (Seneschallie der Grafen von Anjou) versehen werden konnten ${ }^{8}$ ). Anders in Deutschland. Dort knüpfte man an den karolingischen Hof an. An diesem war im 9. Jahrhundert das Amt des Kämmerers mit dem des Pfalzgrafen verbunden worden ${ }^{9}$ ). Das drückte auf die Stellung der übrigen Hofbeamten so, dass nurmehr Ministerialen als solche verwendet werden konnten. Dabei blieb es auch in deutscher Zeit. Nur „bei den Krönungsfeierlichkeiten oder bei Hoftagen übernahmen, da eben fürstliche Hofwürdenträger, wie sie die Feier des Augenblicks verlangte, nicht vorhanden waren, die Herzöge zu Ehren des Königs ausserordentlicher Weise die Hofämter ${ }^{10}$ ).

1) II S. $340 \mathrm{ff.}-{ }^{2}$ ) II S. $341 \mathrm{ff.}-{ }^{3}$ ) II S. $347 \mathrm{ff.} \mathrm{-} \mathrm{4)} \mathrm{II} \mathrm{S.} 349$, 415. - 5) Von denen bald der Erste als maiordomus oder sevescalcus, bald der Letzte die führende Stellung hat, bald auch der gleich zu erwähnende spätere Fünfte II S. 322 . - ') II S. 320 ff. - ") II S. $322 \mathrm{ff.}$ $-{ }^{8}$ ) II S. $\left.326 \mathrm{ff} ., 337 \mathrm{f} .-{ }^{9}\right)$ II S. $336 \mathrm{f} .-{ }^{10}$ ) II S. $337 \mathrm{f} ., 325,328 \mathrm{ff}$. 
Freilich hatte inzwischen der Pfalzgraf die überragende Stellung am Hofe schon geraume Zeit eingebüsst. In Frankreich war sein richterliche und Verwaltungsbefugnisse umschliessendes Amt zu einer blossen Titulatur herabgesunken ${ }^{1}$ ). In Deutschland hatten sich die vier Pfalzgrafen in Provinzialbeamte verwandelt, von denen aber nur der eine es zu einer hervorragenden Stellung brachte, der Pfalzgraf bei Rhein ${ }^{2}$ ). Dies darum, weil unter dem Staufer Konrad das rheinfränkische „Herzogthum mit der lothringischen Pfalzgrafschaft vereinigt wurde, aber so, dass nun das Ganze den letzteren Namen trug ("3). Auf den Ducat in Rheinfranken gehe namentlich die erste Stimme zurück, die der rheinische Pfalzgraf bei der Königswahl unter den weltlichen Kurfürsten habe ${ }^{4}$ ), sowie die Stellung als weltlicher Richter des Königs ${ }^{5}$ ), während das gesetzliche Recht der Reichsverwesung für die terra juris Franconici gleich dem entsprechenden des Herzogs in Sachsen für das Gebiet des sächsischen Rechtes aus der Verbindung von Pfalzgrafenrecht und Herzogsgewalt entsprungen sei ${ }^{6}$ ).

\section{VIII.}

Nur Weniges braucht dem bisher Ausgeführten noch hinzugefügt zu werden, damit durch einen Abriss der Geschichte des Königthums, wie Mayer sie sich denkt, unsere Skizze vollständig wird.

„In der germanischen Frühzeit hat sich allmählich das Königthum wie alle Fürstengewalt von der souveränen Gewalt der Gemeinde abgelöst" ${ }^{\text {" }}$ ). Dem Volk ist der König entsprossen, ein Volksgenosse bleibt er. Gerade darum unterwirft ihn nachmals wenigstens das deutsche Recht mit seiner Person und mit seinem Vermögen dem vom Pfalzgrafen präsidirten Fürstengericht ${ }^{8}$ ). Einst war der König ein Markherr ${ }^{9}$ ) und Holzgraf ${ }^{10}$ ) gleich den anderen Klein-

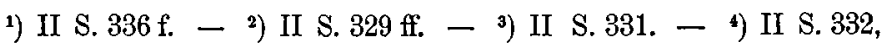

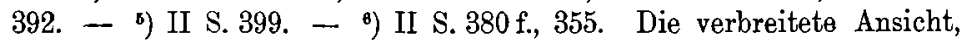
dass die Pfalzgrafschaften durch die Ottonen als Gegengewicht gegen die Herzogthümer errichtet worden seien, wird II S. 336 verworfen;

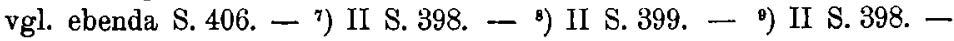
10) I S. 453. 
fürsten, nur dass es ihm später gelang, seinen Wildbann und sein Recht an den Bergschätzen auf ein grosses Reich zu übertragen ${ }^{1}$ ). Auch hatte er den militärischen Oberbefehl ${ }^{2}$ ). Der Heerbann, mit dem er ihn ausübte, ist der älteste Anwendungsfall des späteren Königsbannes ${ }^{3}$ ), nicht etwa der Gerichtsbann. Für den Heerzug und unter Strafe dieses Heerbannes wurde der Unterthaneneid geschworen ${ }^{4}$ ); hervorgegangen vielleicht aus dem Treueid einer erweiterten Gefolgschaft ${ }^{5}$ ) unterwarf er dem König die Unterthanen als Eidverbundene und verpflichtete er sie, wenigstens nach einer in fränkischer Zeit zur Herrschaft gelangenden Vorstellung, zur Unterlassung der schwereren Delicte ${ }^{6}$ ). Dazu stand dem König die Einhebung der öffentlichen Strafgefälle $\mathrm{zu}^{7}$ ), eine Aufgabe, bei deren Erfüllung wir ihn später von dem Grafen oder den Schultheissen unterstützt sehen ${ }^{8}$ ), und vor Allem hatte er die Friedlosigkeit zu vollstrecken, die das Volksgericht verhängte ${ }^{9}$ ), also den Aechter zu bannen ${ }^{10}$ ).

Von solchem Kleinkönigthum erhob sich Chlodowech durch die Gründung des fränkischen Reiches zum Grosskönigthum mit gewaltig gesteigerter Macht ${ }^{11}$ ). Nicht nur aus dem Erbe der römischen Herrschaft bereicherten sich die Merowinger und das ihnen nachfolgende karolingische Königthum, wie etwa durch Herübernahme eines Theils der in straffer Unterordnung gehaltenen römischen Aemter ${ }^{12}$ ) oder durch Aneignung von Steuern ${ }^{13}$ ), herrenlosem Gut, Domänen und von Institutionen wie die Immunität ${ }^{14}$ ). Am meisten wurde erreicht durch kühne Entfaltung angestammter Einrichtungen und Rechtsgedanken sowie durch thatkräftige Neubildung. Davon wie die Ausdehnung des Königszinses, die stärkere Anspannung der Heerpflicht durch Benutzung der Gefolgschaft und der Waffenreichung und die Aufnahme der Kaufleute in das Gesinde, die nachmals das Marktrecht und die für die nachfränkischen Könige so wichtige Stadtherrschaft erzeugte, das Königthum gekräftigt haben, war

1) I S. $454 .-{ }^{2}$ ) II S. 398 , I S. 86 ff., 90, 92. - ${ }^{3}$ ) I S. 150. 4) I S. 1 mit N. 1, S. 8, 150. - 5) I S. 4, II S. 398, oben S. 136 A.4. -) I S. 195. - 7) I S. 229 ff., 232 , II S. $398 .-$ s) oben S. 160 . - 9) I S. $200,209,211,212,213$, II S. $398 .-{ }^{10}$ ) I S. 212 , II S. 400 . ${ }^{11}$ I S. 454, 483. - ${ }^{12}$ ) oben S. 155f. - ${ }^{13}$ ) I S. $53 \mathrm{ff} .{ }^{14}$ ) oben S. 165. 
schon die Rede ${ }^{1}$ ). Fast noch wichtiger war, dass die jetzt sehr häufige Ergebung in den Königsschutz zahllose Unterthanen unter die herrschaftliche Hochgerichtsbarkeit des Königs brachte ${ }^{2}$ ), die er in dem nunmehr hervortretenden Hof- oder Pfalzgericht - eben wegen ihres herrschaftlichen, nicht volksrechtlichen Ursprungs - als Billigkeitsjustiz ${ }^{3}$ ) üben konnte, indes er in früher ${ }^{4}$ ) geschilderter Weise durch seine Grafen die volksrechtlichen Hochgerichte sich unterthan machte ${ }^{5}$ ) und durch die Gerichtsbarkeit über das Domanialgesinde den Grund legte zu den späteren kaiserlichen Landgerichten ${ }^{6}$ ). Vor allem erwarb jetzt der König die so überaus wichtige arbiträre Strafgewalt ${ }^{7}$ ) und mit ihr das Begnadigungsrecht ${ }^{8}$ ). Das Volksrecht billigte ihm nur den durch das dreifache Wergeld geschützten Burgfrieden zu ${ }^{9}$ ). Der König aber dingte, wie übrigens nachmals auch der Herzog und Markgraf ${ }^{10}$ ) bei eigenen Hulden ${ }^{11}$ ), d. h. er verhängte ausserhalb des ordentlichen Gerichts den Tod oder willkürliche Ablösungsstrafen, Harmscharen, über alle, die ihn in seiner Person oder durch Missachtung seiner Befehle oder durch Verletzung seiner Schutzbefohlenen und Beamten kränkten ${ }^{12}$ ). Je länger um so mehr legten überhaupt Strafverfahren und Strafrecht Zeugniss ab von dem wachsenden Einfluss der Obrigkeit. Karl der Grosse führt ein amtliches Ermittelungsverfahren gegen die latrones famosi ein ${ }^{13}$ ); mit heimlicher Frage wird von Amts wegen gegen den Dieb vorgegangen, und so durch Verhaftung, falls er sich vor Gericht nicht $z \mathfrak{u}$ reinigen vermag, die Verurtheilung zum Tod bezw. zur Verbannung oder Gefängniss herbeigeführt. Noch

1) oben S. 125, $146 \mathrm{ff}$. Siehe auch II S. 400. - ${ }^{2}$ ) II S. 111: „Dem König als solchem kommt ursprünglich Gerichtsbarkeit überhaupt nicht zu weder erstinstanzliche noch Recursgerichtsbarkeit. " Dazu ebenda

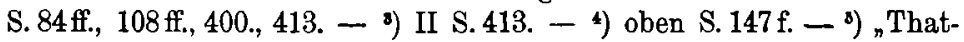
sächlich ist schon in der fränkischen Zeit die königliche Rechtsprechung in das ganze Rechtssystem eingegliedert, und die Provinzialgerichte werden von den königlichen Beamten abhängig. So ist doch die Rechtsprechung und damit das wesentliche Arbeitsfeld des mittelalterlichen Staates ein königliches Recht geworden" II S. 400. ${ }^{\circ}$ II S. $301 \mathrm{f} .-{ }^{7}$ ) II S. $92 \mathrm{ff} .-{ }^{8}$ ) II S. $\left.106 \mathrm{ff} .-{ }^{9}\right)$ II S. $84 \mathrm{ff} .-$ $\left.{ }^{10}\right)$ II S. 92, 367, 376. - ${ }^{11}$ ) II S. $98 \mathrm{ff} ., 399$. - $^{12}$ ) II S. $101 \mathrm{ff} ., 103 .-$ 1s) I S. $282 \mathrm{f}$. 
vorher war die handhafte That in die blosse Notorietät umgebildet worden, wodurch „das fränkische Recht mit seiner intensiven Auffassung von der staatlichen Gewalt, die ihm durch ganz Europa zum Siege verholfen, dem königlichen Richter das zugesprochen hatte, was ursprünglich der Rache des Einzelnen und dem Zugriff der Gesammtheit überlassen war" ${ }^{1}$ ). Und ebenso nahm in karolingischer Zeit das Königsrecht aus dem Volksrecht die Rüge herüber ${ }^{2}$ ), um sie auch in Königsbannsachen und später in Friedensbruchsachen in weitestem Umfang zur Anwendung zu bringen ${ }^{3}$ ). Dadurch, dass der missbräuchlich selbständig, ja neben der ganzen Composition erhobene fredus bei den schwereren, den Gewaltthätigkeitsdelicten ungefähr der königlichen (Heer)Bannbusse gleichkam, entstand die Vorstellung, dass auch diese Delicte unter den Bann, der sich zum Strafbann erweiterte, fielen ${ }^{4}$ ). In nachfränkischer Zeit aber knüpfte sich hieran durch eine Entwickelung, welche der Gottes- und Landfrieden herbeiführte, die Criminalisirung aller unter Königsbann gekommenen Delicte $^{5}$ ).

1) I S. 227; vgl. auch ebenda S. 215 ff. $-{ }^{2}$ ) I S. $243,244 .-$ 3) II S. $233 \mathrm{ff}$., 252, 283: „Die ungeordnete Reaction der Einzelnen und der nichtstaatlichen Verbände hat das Königthum in seine Hand genommen; neben die vorhandene Criminal- und Communalrüge setzte es die Rüge der Brüchten, besonders der Königsbannfälle, und die Rüge der Famosität. Nichts lässt deutlicher als diese Thatsache die Kraft des fränkischen Regiments verstehen. - ${ }^{4}$ ) I S. $191 \mathrm{ff}$; vgl. ebenda S. 150, 189, $194 \mathrm{f}$. - 5) Der Gottes- und Landfriede stimmt einmal überein mit dem Handfrieden (über dessen Form I S. 164f., 184 N.83), der eine Fehde dauernd (pax, im Gegensatz zu der nur unter den fehdeberechtigten Ritterlichen möglichen treuga, dem Waffenstillstand) beilegt; ,der Friede für künftige Delicte erweist sich dem Frieden für die einzelne verübte Gewaltthat nach Form und Wirkung gleich", I S. 184 mit $161 \mathrm{ff}$, , besonders 163, 176 und $182 \mathrm{f}$. Andrerseits knüpft er an den Unterthaneneid an; ,der zeitlich unbeschränkte Unterthaneneid geht in den zeitlich beschränkten Landfriedenseid über" I S. 184 mit S. 5, 183. Die Kirche erzwingt den allgemeinen Eid; doch erleidet die zuerst auch gegen die Fehde der Ritter gerichtete Landfriedensbewegung bald eine Abschwächung durch Zulassung eines bloss ritterlichen, auf einige Tage der Woche beschränkten Gottesfriedens, I S. 177 f., 185 f., 172. Dafür dringt unter dem Einflusse des mittel- und nordfranzösischen und des deutschen Handfriedensbruchrechtes die Todesstrafe als Folge des Schwurfriedensbruches ein und führt so zur Ersetzung der Königs- 
Erscheint so das fränkische Königthum fast als übersättigt, so waren oder wurden die Verhältnisse des nachfränkischen um so bescheidener. Die Provinzialgewalt löste sich eben nunmehr vom Königthum $\mathbf{a b}^{1}$ ), und die Machtmittel des öffentlichen Rechts gingen an die Grossen über ${ }^{2}$ ). Unter ihnen stehen obenan die Herzöge, für deren Gewalt die Verlehnung der Einkünfte der Grafschaften und das karolingische Missaticum die Grundlage bildet ${ }^{3}$ ), wozu noch der Erwerb von Titel und Reifen des dux ${ }^{4}$ ) und im Osten namentlich die Wahl zur Heerführerschaft ${ }^{5}$ ) kamen. Doch noch wirksamer war die Beeinträchtigung der königlichen Gewalt durch die Grafen, denen in nachfränkischer Zeit, um von Anderem zu schweigen ${ }^{6}$ ), der Königszins mit dem Eigenthum am Lande der Schatzpflichtigen ${ }^{7}$ ), das Wildfangsrecht ${ }^{8}$ ) und die Rügebefugniss ${ }^{9}$ ) zufiel, und welche aus dem Recht des Königs auf öffentliche Fronden sich ein sachlich unbegrenztes, nur zeitlich beschränktes Recht auf Frondienste der Freien zu Gunsten ihrer eigenen Wirthschaft schufen ${ }^{10}$ ). In Frankreich hatten die späteren Karolinger sogar das Königsgut an die Grossen verschleudert ${ }^{11}$ ), und gelang es den Grafen und Baronen, selbst den Unterthaneneid ${ }^{12}$ ), den Heerbann ${ }^{13}$ ) und den Wildbann ${ }^{14}$ ), das Münzrecht ${ }^{15}$ ) sowie die Rechte über die Personen zu erwerben, die sich ursprünglich in den Königsschutz begeben hatten ${ }^{16}$ ), und damit auch das Marktrecht ${ }^{17}$ ).

Gleichwohl arbeitete sich das anfänglich mit nicht viel mehr als mit den Machtmitteln der Herzogsgewalt in Francien $\left.^{18}\right)$, mit einer im Süden versagenden dürftigen Lehensherrlichkeit ${ }^{19}$ ), mit einem Rest von oberster Gerichtsbarkeit ${ }^{20}$ ) und Heerführerschaft ${ }^{21}$ ) ausgestattete französische Königthum ${ }^{22}$ )

bannstrafe durch Criminalstrafen, I S. 174, 183, 185, 195, 144, 166, II S. 399 .

1) II S. 350. - 2) II S. 401: „Der Streit um die Staatsgewalt, d. h. um die Rechtsprechung wird jetzt doch nicht mehr zwischen Fürst und dem unabhängigen Volksverbande gekämpft, sondern dem König und seinen Beamten." - ${ }^{\text {s) }}$ II S. $362 \mathrm{ff.,} \mathrm{369.} \mathrm{-}{ }^{4}$ ) II S. 361, 369. ø) II S. 370. - ${ }^{\text {b) }}$ II S. $402 \mathrm{f}$. - 7) oben S. $126 \mathrm{f}$. - ${ }^{8}$ ) I S. $106 \mathrm{ff}$ 9) I S. $263 \mathrm{ff} .{ }^{10}$ ) I S. 70, 71. - ${ }^{11}$ ) II S. 405. - $^{12}$ ) I S. $4 \mathrm{ff.}-{ }^{13}$ ) I S. $126,133 .-{ }^{14)}$ I S. $90 .-{ }^{15}$ ) I S. $94 \mathrm{f} .-{ }^{16}$ ) II S. $405 .-{ }^{17}$ ) II S. $263 \mathrm{ff.}-{ }^{18}$ ) II S. $406,414 .-{ }^{19}$ ) II S. $414 \mathrm{f}$; ; siehe oben S. $162 .-$ ${ }^{20}$ ) II S. 108 f., $96 .{ }^{21}$ ) II S. 414 f. - ${ }^{22}$ ) I S. 172. 
172 Ulr. Stutz, Grundl. d. mittelalt. Verf. Deutschl. u. Frankr.

langsam aber sicher zu achtunggebietender Stärke und zum Einheitsstaat ${ }^{1}$ ) empor, wozu namentlich die Thatkraft beitrug, mit der es sich auf die Gottesfriedensverbände stützte ${ }^{2}$ ) und in der Gerichtsbarkeit über die cas royaux die arbiträre Strafgewalt ausnutzte ${ }^{3}$ ), sowie der Umstand, dass die Dynastie der Capetinger so lange lebte als die französische Monarchie, sodass ein Wahlkönigthum sich nicht ausbilden konnte, vielmehr das Erbprincip in unerschütterter Geltung blieb ${ }^{4}$ ).

Umgekehrt sank das deutsche Königthum, das anfänglich mit der ganzen Machtfülle der Karolinger, insbesondere mit den Domänen ${ }^{5}$ ), bekleidet war und z. B. seine mit derjenigen der Provinzialgerichte concurrirende Gerichtsbarkeit auf den Reisen des Hofs kraftvoll ausnützte ${ }^{6}$ ), nach und nach zum Schatten herab. Mit die Hauptschuld trug daran der Wechsel der Dynastien und die Königswahl ${ }^{7}$ ), bei der nach dem Vorbild der kirchlichen Wahl ein (-verdoppeltes) Scrutatorencolleg die Entscheidung herbeiführte, aus dem nachmals die Kurfürsten mit ausschliesslichem Wahlrecht hervorgingen ${ }^{8}$ ). Nicht minder verderblich wirkten aber "der jugendliche Ueberschwang und das jugendliche Unvermögen des deutschen Lebens, die im Zuge zum Imperium und in dem Mangel aller technischen, staatlichen Centralbehörden lagen" 9). So wurde bei uns in Deutschland die Reichsgewalt zerstört ${ }^{10}$ ), und war für lange Zeit allein die Landesgewalt lebenskräftig.

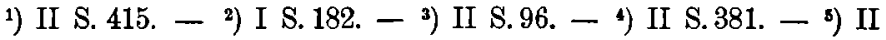

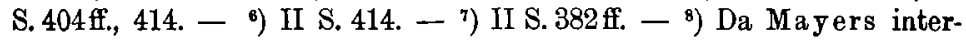
essante Ausführungen über die Königswahl bereits durch Alfred v. Wretschko in Bd. XX 1899 dieser Zeitschrift S. $168 \mathrm{f}, 170 \mathrm{mit}$ N.4, 188 mit N.2 u. ö. dargelegt und in durchaus zutreffender Weise discutirt worden sind, glaube ich mich mit diesen kurzen Andeutungen begnügen zu können. - ${ }^{\text {?) }}$ II S. 415. - 10) Ueber die Reste königlicher Gewalt, die am Ende noch geblieben sind, vgl. II S. $407 \mathrm{ff}$.

Druckfehler-Berichtigung. S. 131 wolle man in der Anmerkung Zeile 23 statt biergeldon lesen: bargildon. 